\title{
MAP 1A and MAP 1B Are Structurally Related Microtubule Associated Proteins with Distinct Developmental Patterns in the CNS
}

\author{
Thomas A. Schoenfeld," Lisa McKerracher, ${ }^{b}$ Robert Obar, and Richard B. Vallee \\ The Worcester Foundation for Experimental Biology, Shrewsbury, Massachusetts 01545
}

Five high-molecular-weight microtubule-associated proteins (MAPs) were identified in brain tissue in previous work from this laboratory (Bloom et al., 1984). These proteins were termed MAP 1A, 1B, 1C, 2A, and 2B. The MAP 1's differed from the MAP 2's, and showed little evidence of interrelationship on the basis of immunological and biochemical comparison. We report here that MAP $1 A$ and MAP 1B are, in fact, related at the level of subunit composition. Immunoprecipitation of the individual MAPs showed that both contained low-molecular-weight subunits of $M_{r}, 30,000$ and $M_{r}$ 19,000 (light chains 1 and 3 ). An additional subunit, light chain $2(M, 28,000)$, was primarily found in preparations of MAP 1A. The light chains co-sedimented with microtubules after chymotryptic digestion of the MAPs. This suggested an association of the light chains with the microtubule binding domains of the MAPs, which are identified here as distinct fragments of $M, 60,000$ for MAP $1 A$ and 120,000 for MAP 1B. A panel of monocional anti-MAP $1 A$ and anti-MAP $1 B$ antibodies, including one that reacts with a common phosphorylated epitope, was used to examine the distribution of these proteins in the developing rat brain and spinal cord. MAP 1B was found to be abundant in the newborn brain and to decrease with development, in contrast to MAP $1 \mathrm{~A}$ which increased with development. By immunohistochemistry MAP 1B was found to be highly concentrated in developing axonal processes in the cerebellar molecular layer, the corticospinal tract, the mossy fibers in the hippocampus, and the olfactory nerve. Of particular interest, the mossy fiber and olfactory nerve staining persisted in the adult, indicating continued outgrowth of the mossy fibers as well as olfactory nerve axons. MAP 1A staining was, in contrast, weak or absent in developing axonal fibers but moderate in mature axons and intense in developing and mature dendritic processes. Our results indicate that MAP 1 A and MAP $1 B$ are structurally related components of the neuronal cytoskeleton with complementary patterns of expression.

Received June 20, 1988; revised Aug. 29, 1988; accepted Aug. 29, 1988.

We thank Frank Luca for his help in the early stages of the immunocytochemical experiments, Dr. James Crandall for his extensive help with the analysis of rat developmental neuroanatomy, Drs. James Hammarback and Christine Collins for their critical reading of the manuscript, and Dr. Foteos MacRides for his coopcration during completion of the immunocytochemical cxpcriments. This work was supported by NIH Grant GM26701 to R.B.V.

Correspondence should be addressed to Dr. Richard B. Vallee, Worcester Foundation for Experimental Biology, 222 Maple Avenue, Shrewsbury, MA 01545.

a Present address: Department of Psychology, Clark University, Worcester, MA 01610.

${ }^{\circ}$ Present address: Department of Neurology, Montreal General Hospital, 1650 Cedar Ave., Montreal, Quebec, Canada, H3G 1 A4

Copyright (C) 1989 Society for Neuroscience $0270-6474 / 89 / 051712-19 \$ 02.00 / 0$
The high-molecular-weight MAPs (microtubule-associated proteins) of brain tissue are a diverse group of proteins involved in microtubule assembly regulation, cytoskeletal organization, and organelle transport. Our laboratory has described 5 polypeptide species, which we termed MAP 1A, MAP 1B, MAP 1C, MAP 2A, and MAP 2B (Bloom et al., 1984, 1985a). MAP 2A and MAP $2 \mathrm{~B}$ appear to be closely related. They have a number of features distinguishing them from the MAP 1's (reviewed in Vallee et al., 1986), including stability to elevated temperature and phosphorylation by an associated cAMP-dependent protein kinase. The MAP 2 species are found primarily in dendrites, while MAP 1A and MAP 1B are present in axons and glial cells as well. MAP 2 has served as a model for understanding the structure of the MAPs. Analysis of proteolytic digestion products revealed that most of the MAP 2 molecule represents a fibrous projection protruding from the microtubule surface. Chymotryptic fragments of $M, 32,000$ and 34,000 were found to contain the relatively small microtubule binding domain of the molecule. Recently, the full sequence of MAP 2 and its binding domain have been determined (Lewis et al., 1988).

The properties of the MAP 1's are less well understood. They show complex and variable electrophoretic behavior, including splitting and shifting in relative mobility under different electrophoretic conditions (Bloom et al., 1984; Herrmann et al., 1985; de Mey et al., 1987; Paschal et al., 1987). Their relative abundance in purified microtubules depends on brain region (Vallee, 1982), brain age (Binder et al., 1984; Calvert and Anderton, 1985; Kumagai et al., 1985; Riederer and Matus, 1985) and the presence of nucleotides during microtubule purification (Paschal et al., 1987). The use of monoclonal antibodies produced against the MAP 1 species has led to diverse descriptions of their distribution and properties. Thus, antibodies to components of the MAP 1 electrophoretic complex have been reported to react with stress fibers (Asai et al., 1985), centrosomes and kinetochores (Bonifacino et al., 1985; de Mey et al., 1987), and nuclear spots (Sato et al., 1984), as well as with neuronal processes and glial cells (Bloom et al., 1984, 1985a; Huber and Matus, 1984; Calvert and Anderton, 1985). Even in the latter cases, striking differences in the relative distribution of MAP 1 species were seen within the neuron and between cell types, as well as during development of the nervous system. Underlying these disparate results and the diversity in nomenclature that has been employed for these proteins ${ }^{1}$ is the lack of information regarding the molecular relationship between the MAP 1 species.

'Names that have been used for MAPs in the MAP 1 molecular-weight range include MAP 1A, B, and C (this laboratory: Bloom et al., 1984, 1985a), MAP 5 (Riederer et al., 1986). MAP 1X (Calvert and Anderton, 1985), MAP X (Binder et al., 1984), and MAP 1.1 and 1.2 (Greene etal., 1983). 
In addition, some antibodies to the MAP l's clcarly recognize phosphorylated epitopes that are shared with other proteins (Luca et al., 1986; de Mey et al., 1987), and this may have contributed to the diversity in subcellular distribution patterns.

We have recently purified MAP $1 \mathrm{C}$ and found that it is a microtubule-activated ATPase, capable of translocating microtubules in an in vitro gliding assay (Paschal et al., 1987). Based on the direction of force production along microtubules, we have proposed that it is responsible for retrograde axonal transport (Paschal and Vallee, 1987). Analysis of the protein by scanning transmission electron microscopy revealed that it is indistinguishable in size and structure from the ciliary and flagellar ATPase dynein (Vallee et al., 1988). It thus represents a cytoplasmic form of this enzyme and is structurally and functionally distinct from any of the other high-molecular-weight MAPs.

Less is known about the function and properties of MAP 1A and MAP 1B. They are observed as elongated fibrous proteins that decorate the microtubule surface (Vallee and Davis, 1983; Hirokawa et al., 1985; Shiomura and Hirokawa, 1987). In this respect they seem similar to the MAP 2 polypeptides (Voter and Erickson, 1982). In other respects they differ from the other MAPs. Unlike MAP 2, which is almost exclusively found in dendrites, both MAP 1A and MAP 1B are found throughout the neuronal cell, as well as in glial cells and other cell types outside of the nervous system (Bloom et al., 1984a, 1985a). In addition, they have shown no evidence for associated protein kinase or ATPase activities like MAP 2 and MAP 1C. Chromatographic preparations of MAP $1 \mathrm{~A}$ and MAP $1 \mathrm{~B}$ do contain "light chains" (Vallee and Davis, 1983). These species are distinct from subunits identified in MAP 2 (Theurkauf and Vallee, 1982) and MAP 1C (Paschal et al., 1987), but their function is, as yet, unknown.

Existing evidence suggests relatively little primary structural similarity between MAP $1 \mathrm{~A}$ and MAP 1B. Eleven of 12 monoclonal antibodies raised against these proteins in our laboratory were specific for either MAP 1A or MAP 1B (Bloom et al., 1984, 1985a; Vallee and Luca, 1985). One antibody did cross-react with a phosphorylated epitope present in both proteins (Luca et al., 1986). However, no evidence for extensive sequence homology between MAP $1 \mathrm{~A}$ and MAP $1 \mathrm{~B}$ was obtained by peptide mapping (Bloom et al., 1985a; Herrmann et al., 1985), or by Northern blot analysis using a cDNA probe corresponding to a microtubule-associated protein of the size of MAP 1B (Lewis et al., 1986).

The present study was undertaken to investigate further the relationship between MAP $1 \mathrm{~A}$ and MAP $1 \mathrm{~B}$. We find that, despite the observed differences between the 2 proteins, they contain common light-chain subunits and, therefore, appear to be related with regard to higher-order structure. We also find that, despite the widespread expression of MAP 1A and MAP 1B throughout the CNS of the adult (Bloom et al., 1984, 1985a), these proteins show a distinct but complementary distribution in axons and dendrites during development.

\section{Materials and Methods}

Antibodies. Five anti-MAP 1B and 7 anti-MAP 1A antibodies were prepared as described previously (Bloom et al., 1984, 1985a; Vallee and Luca, 1985). The antibodies are named MAP $1 \mathrm{~A}-1,-2,-3,-4,-5,-6$, and -7 and MAP $1 \mathrm{~B}-1,-2,-3,-4$, and -5 , the names referring to the antigen and the order of isolation of the hybridoma clones. All but one of the antibodies are of the IgGl subclass. The exception is "MAP 1B3 ," an IgM that was raised against purified MAP 1B but that recognizes a phosphorylated cpitope on MAP 1B, MAP 1A, and the high- and middle-molecular-weight neurofilament polypeptides (Luca et al., 1986). Antibody MAP 1A-7 reacted with multiple polypeptides on immunoblots and, therefore, was not used for most of the other types of analysis described here. The other anti-MAP 1A and anti-MAP 1B antibodies have been judged to react with distinct epitopes within the respective MAPs based on cultured cell immunofluorescence patterns (Bloom et al., 1985a; Vallee and Luca, 1986; Vallee et al., 1986; and unpublished observations), differences in species cross-reactivity, and differential reactivity to bacterially expressed fusion proteins (Hammarback et al., 1989).

\section{Biochemical methods}

Microtubule preparation and digestion. Microtubules were prepared by reversible assembly from whole calf brain (Vallee, 1986a) or from calf brain white matter using taxol (Vallee, 1986b). In both cases the microtubules were resuspended to $2 \mathrm{mg} / \mathrm{ml}$ in PEM buffer $(0.1 \mathrm{M}$ Pipes, pH 6.6, 1 mM EGTA, $\left.1 \mathrm{~mm} \mathrm{MgSO}_{4}\right)$ containing taxol $(20 \mu \mathrm{M})$, and digested with $0.35 \mu \mathrm{g} / \mathrm{ml}$ chymotrypsin (Worthington Biochemical) at $37^{\circ} \mathrm{C}$ for $5 \mathrm{~min}$. The reaction was stopped using $1 \mathrm{~mm}$ phenylmethyl sulfonyl fluoride (PMSF). Microtubule binding and nonbinding fragments of the MAPs were separated by centrifugation of the microtubules as described previously (Vallee, 1980,1986a), and the binding fragments were dissociated from the microtubules with $0.35 \mathrm{M} \mathrm{NaCl}$ (Vallee, 1982).

Immunoprecipitation. Calf or rat brain tissue was homogenized using a Potter-Elvejhem Teflon pestle homogenizer in 1 vol PEM buffer or in $50 \mathrm{~mm}$ Pipes, $50 \mathrm{~mm}$ HEPES, $2.0 \mathrm{~mm}$ EDTA, pH 7.0, in either case containing $0.5 \mathrm{mM}$ DTT, $1 \mathrm{mM}$ PMSF, $10 \mu \mathrm{g} / \mathrm{ml}$ leupeptin, and $10 \mu \mathrm{g} /$ $\mathrm{ml}$ TAME. This and all subsequent steps were at $0-4^{\circ} \mathrm{C}$. The homogenate was centrifuged successively at $25,000 \times g$ for $30 \mathrm{~min}$, and at 150,000 $\times g$ for $90 \mathrm{~min}$. The supernatc (cytosolic cxtract) was used fresh or after freezing in liquid nitrogen and storage at $-80^{\circ} \mathrm{C}$. Nonidet $\mathrm{P}-40$ was added to $1 \%$, and the primary antibody as ascites fluid or as hybridoma culture supernate was added $(5 \mu \mathrm{l}$ and $1 \mathrm{ml}$, respectively, per $\mathrm{ml}$ of cytosolic extract) and incubated for $2 \mathrm{hr}$. Goat antibody (anti-mouse immunoglobulins) conjugated to Sepharose beads (Hyclone) was added and incubated overnight with gentle agitation. The beads were washed 4-5 times in Tris-buffered saline $(50 \mathrm{~mm}$ Tris/ $\mathrm{HCl}, \mathrm{pH} 7.4,150 \mathrm{~mm}$ $\mathrm{NaCl}$ ), and extracted with SDS gel electrophoresis sample buffer (Laemmli, 1970) lacking 2-mercaptoethanol to avoid extracting the goat antimouse antibody. The beads were removed by centrifugation at $1000 \times$ $g$, 2-mercaptoethanol was added to $5 \%(\mathrm{vol} / \mathrm{vol})$, and the sample was boiled for 1-5 min.

Electrophoresis and immunoblotting. SDS gel electrophoresis was performed using the method of Laemmli (1970). Gels were stained with Coomassie Brilliant blue R250, and the individual bands were analyzed quantitatively by densitometry using a Helena Quik-scan Jr gel densitometer (Vallee and Davis, 1983). Immunoblotting was performed essentially as described previously (Bloom et al., 1984). The blots were incubated in $0.1 \%$ Amido black in 5:5:1 methanol:water:acetic acid to visualize total protein or in primary mouse monoclonal antibody (ascites fluid at $1: 1000$ ) overnight. The antibody reaction was visualized by incubation of the blot for $1 \mathrm{hr}$ in alkaline phosphatase-conjugated sheep anti-mouse IgG (Promega Biotech) followed by reaction in nitro blue tetrazolium and bromo-4-chloro-3-indolyl phosphate (Sigma) for 1-5 min (Blake et al., 1984). The reaction was quantified hy densitometry of reflected light using an LKB Ultrascan SL Densitometer and corrected for nonlinearity against a standard curve constructed from blots of purified brain microtubules.

\section{Immunocytochemistry}

Brain and spinal cord tissues were obtained from neonatal [postnatal (P) days 0-20, P0-20] and adult rats. Animals were perfused transcardially with PBS ( $50 \mathrm{~mm}$ sodium phosphate, $\mathrm{pH} 7.4,0.9 \%$ sodium chloride) followed by paraformaldehyde/lysine/periodate (McLean and Nakane, 1974; Crandall et al., 1986) or, alternatively, paraformaldehyde/picrate (Stefanini et al., 1967; Bloom et al., 1984). Following dissection, tissues continued to be incubated in fixative for at least $2 \mathrm{hr}$. Sections (30-50 $\mu \mathrm{m})$ were cut with a vibrating microtome (Vibratome, Lancer Instruments) and collected in $0.1 \mathrm{M}$ sodium phosphate buffer, pH 7.4 (PB). Alternatively, sections $(20 \mu \mathrm{m})$ were cut with a freezing sledge microtome (American Optical). They were then processed freefloating in a series of solutions for indirect immunofiuorescence as fol- 


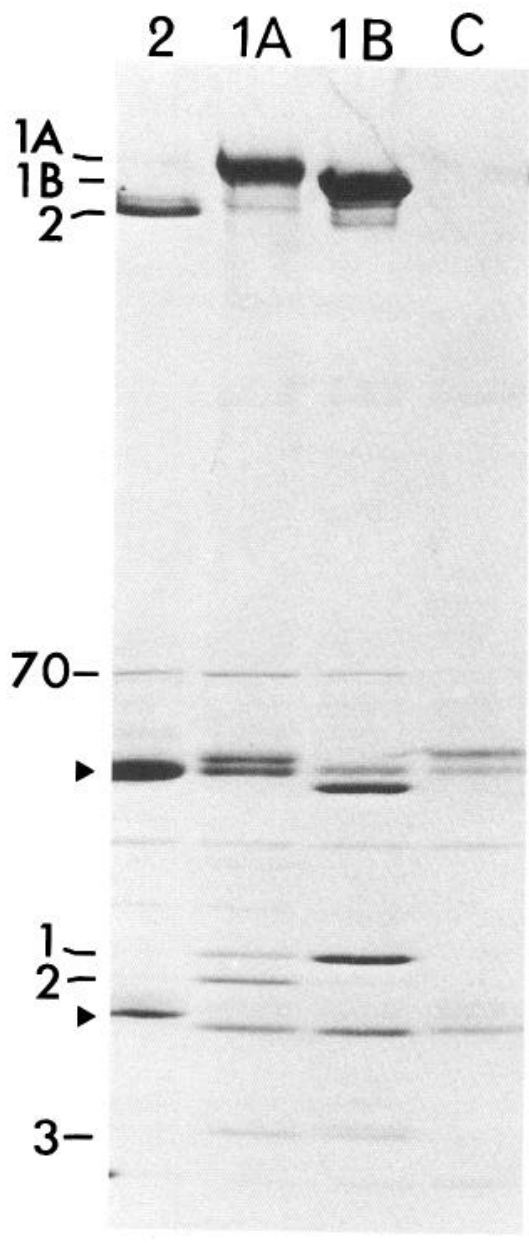

Figure 1. Co-immunoprecipitation of light chains with MAP 1A and MAP 1B from calf brain cerebral cortex. Antibodies used were as follows: 2 , anti-MAP 2 monoclonal; $1 A$, anti-MAP $1 \mathrm{~A}$ (antibody MAP $1 \mathrm{~A}-2$ ); $1 B$, anti-MAP 1B (antibody MAP 1B-4); $C$, control anti-sea urchin $77 \mathrm{kDa}$ MAP (S.p.77-4; Bloom et al., 1985b). Gel is made from 4-14\% acrylamide gradient. Light chains $1-3$ were found in the MAP $1 \mathrm{~A}$ and MAP $1 \mathrm{~B}$ lanes, and a $70 \mathrm{kDa}$ polypeptide was found in all of the brain MAP lanes. Antibody heavy and light chains are indicated by arrowheads.

lows: (1) $10 \%$ normal sheep serum in PB containing $0.02 \%$ Triton $\mathrm{X}-100$ (TX), overnight at $4^{\circ} \mathrm{C} ;(2)$ mouse monoclonal culture medium containing $0.02 \% \mathrm{TX}, 24-48 \mathrm{hr}$ at $4^{\circ} \mathrm{C}$; (3) PB containing TX, $4-51 \mathrm{hr}$ rinses; (4) sheep-anti-mouse IgG (Cappel Laboratories) conjugated with rhodamine in this laboratory (Bloom et al., 1984), diluted 1:20 in PB containing $5-10 \%$ normal sheep serum and $0.02 \%$ TX, overnight at $4^{\circ} \mathrm{C}$; (5) PB, 4-5 $1 \mathrm{hr}$ rinses. Sections were mounted from PB onto chrom alum-subbed slides and coverslipped with polyvinyl alcohol or DPX. Alternatively, following incubation in the primary antibody, sections were processed by the avidin-biotin method using fluorescein-conjugated avidin (Vector Laboratories) in the labeling step.

Alternatives in protocol were used as noted with neonatal tissues to ensure optimal results. Each variation was applied systematically to a group of littermates through the entire age series. Immunocytochemical data are shown for antibodies MAP 1A-1, MAP 1B-3, and MAP 1B4. However, all results were confirmed using other anti-MAP $1 \mathrm{~A}$ and anti-MAP 1B antibodies (MAP 1A-2 and -4; MAP 1B-1, -2, and -5).

\section{Results}

Subunit composition and proteolytic analysis of MAP $1 \mathrm{~A}$ and MAP 1B

Earlier work from this laboratory (Vallee and Davis, 1983) indicated that chromatographically prepared MAP 1 contained 2
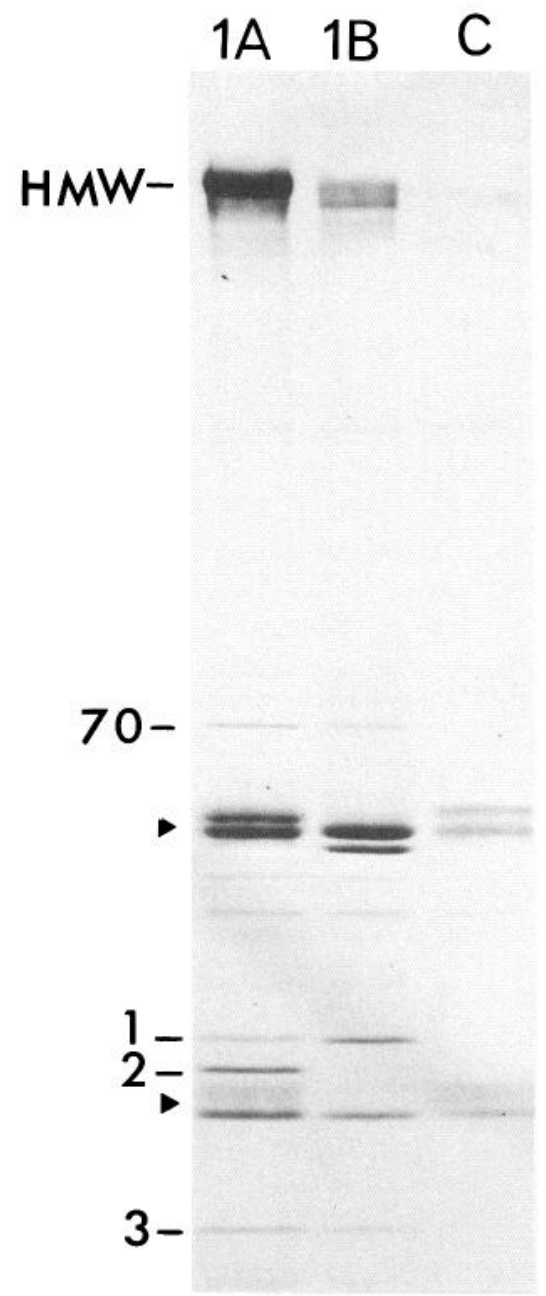

Figure 2. Co-immunoprecipitation of light chains with MAP 1A and MAP 1B from whole rat brain. Conditions and antibodies as in Figure 1. The splitting of MAP 1B that is observed is often seen both by immunoblotting and immunoprecipitation. $H M W$, high-molecularweight MAPs.

low-molecular-weight subunits, referred to as light chains 1 and $2\left(M_{r} 30,000\right.$ and 28,000 , respectively). The presence of an additional light chain, since referred to as light chain 3 (Kuznetsov and Gelfand, 1987), was also noted in these preparations. The chromatographically prepared MAP 1 fraction contained both MAP 1A and MAP 1B, and, thus, it was uncertain which of these proteins contained the light chains.

To address this question, MAP 1A and MAP 1B were each immunoprecipitated under nondenaturing conditions from cytosolic extracts of calf and rat brain tissue (Figs. 1,2). We found that light chains co-immunoprecipitated with both MAP 1A and MAP $1 \mathrm{~B}$ but not with MAP 2 . All 3 light chains were present in the MAP $1 \mathrm{~A}$ immunoprecipitates. Only light chain 1 , at what appeared to be a higher level, and light chain 3 were present in the MAP 1B immunoprecipitates. No light chain 2 was present in the MAP 1B samples shown in Figures 1 and 2, though trace levels could be seen in other experiments. The same relative composition of light chains was observed using 4 different antibodies to MAP 1A (antibody MAP 1A-1, $-2,-3$, and -4) and MAP 1B (antibody MAP 1B-1, -2, -4 , and -5). In addition to the light chains, an $M_{r} 70,000$ species was seen in MAP 1A, 


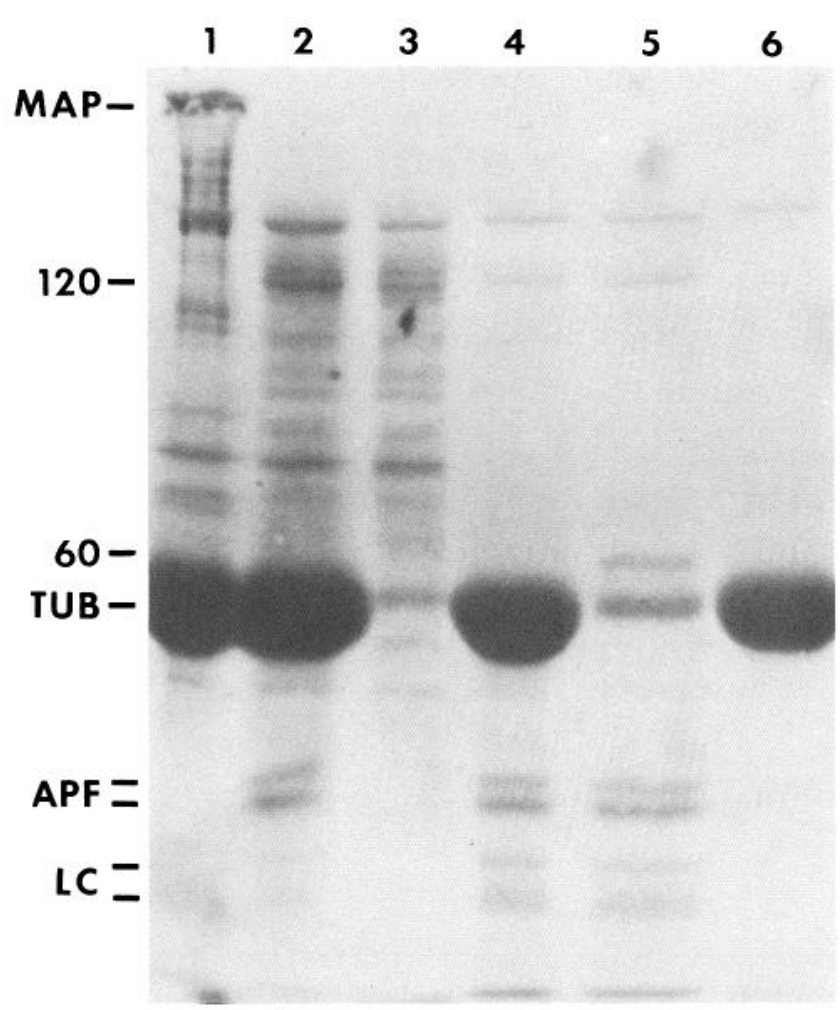

AMIDO BLACK

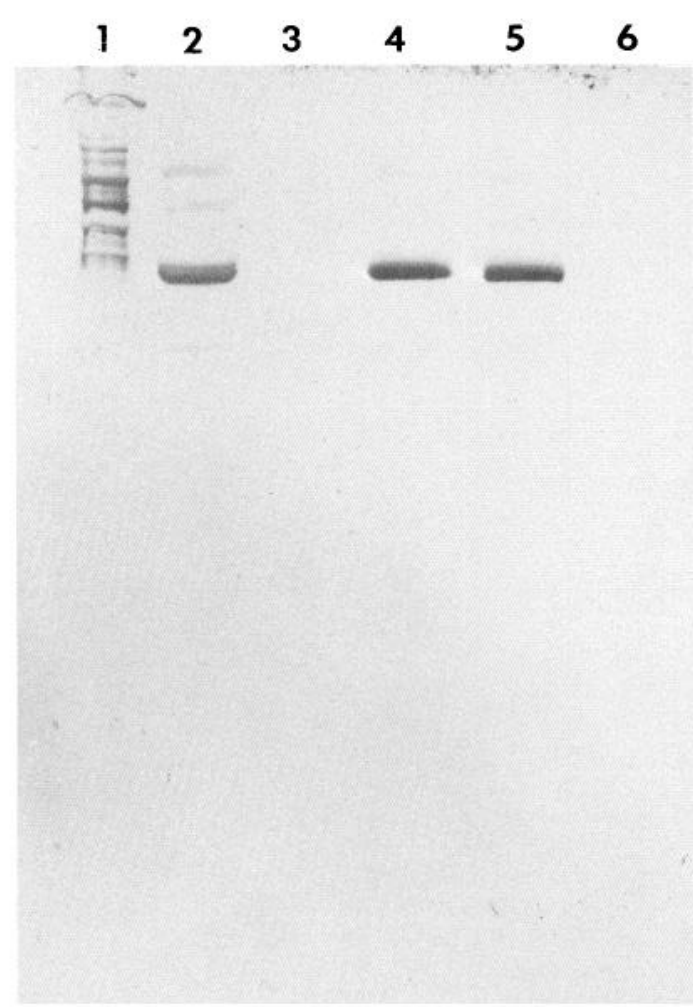

1B-1 BLOT

Figure 3. Chymotryptic digestion of MAPs. Microtubules were prepared from calf brain white matter using taxol and exposed to chymotrypsin. The fragments were then fractionated by microtubule sedimentation with and without added $\mathrm{NaCl}$ to dissociate microtubule binding regions of the MAP molecules. The samples were analyzed by electrophoresis ( $7.5 \%$ polyacrylamide), transferred by electroblotting to nitrocellulose paper, and stained with Amido black (lefi panel) or reacted with anti-MAP 1B (antibody "MAP 1B-1," right panel). 1, Untreated microtubules; 2, total microtubule digest; 3 and 4, supernate and pellet after microtubule sedimentation, respectively; 5 and 6 , supernate and pellet after sedimentation in the presence of $0.35 \mathrm{M} \mathrm{NaCl}$, respectively. $M A P$, high-molecular-weight MAPs; $T U B$, tubulin; $A P F$, MAP 2 assembly-promoting fragments of $M, 32,000$ and 34,$000 ; L C$, light chains 1 and 2 . The positions of $M_{r} 120,000$ MAP 1 B fragment and $M, 60,000$ MAP 1A fragment are indicated at left. A contaminant between the MAP and 120 positions may be seen that is not typically found in these preparations. Microtubule binding fragments are found in lanes 2, 4, and 5. The immunoblot shows a disproportionately high level of intensity of endogenous MAP 1B fragments due to incomplete transfer of the MAP 1B band to the nitrocellulose.

MAP 1B, and also in MAP 2 immunoprecipitates, and appears to be the same protein identified earlier in chromatographically purified MAP 2 (Vallee et al., 1981).

The total content of light chains 1 and 2 ranged from 2.3 to $3.3 \mathrm{~mol} / \mathrm{mol}$ of high-molecular-weight MAP band for both MAP $1 \mathrm{~A}$ and MAP 1B (Table 1). This was close to the value of 2.4 obtained from examination of a chromatographically purified mixture of MAP 1A and MAP 1B (Vallee and Davis, 1983). The values obtained here are somewhat higher than in the earlier study, possibly due to minor degradation of the high-molecularweight species during the prolonged incubations used for immunoprecipitation. Light chain 3 was present at $1-2 \mathrm{~mol} / \mathrm{mol}$ of MAP 1A and MAP 1B. The $M_{r} 70,000$ species was consistently present at substoichiometric levels. Because of its lower abundance and its presence in MAP 2 as well as the MAP 1's, we are less certain of its role as a subunit of the native MAP $1 \mathrm{~A}$ and $1 \mathrm{~B}$ molecules.

To examine further the interaction of the light chains with

Table 1. Molar ratios of MAP 1 subunits

\begin{tabular}{|c|c|c|c|c|c|c|}
\hline \multirow[b]{2}{*}{ Protein } & \multirow[b]{2}{*}{ Source } & \multicolumn{5}{|c|}{ Mol/mol MAP 1 heavy chain } \\
\hline & & LC1 & LC2 & $\mathrm{LC} 1+\mathrm{LC} 2$ & LC3 & $70 \mathrm{~K}$ \\
\hline MAP 1A & calf & $1.4 \pm 0.8$ & $1.9 \pm 1.1$ & 3.3 & $2.0 \pm 0.7$ & $0.4 \pm 0.2$ \\
\hline MAP 1B & calf & $2.6 \pm 1.0$ & & 2.6 & $1.1 \pm 0.6$ & $0.3 \pm 0.2$ \\
\hline MAP 1A & rat & $0.8 \pm 0.3$ & $2.0 \pm 0.8$ & 2.8 & $1.4 \pm 0.4$ & $0.3 \pm 0.0$ \\
\hline MAP 1B & rat & $2.3 \pm 0.3$ & & 2.3 & $1.8 \pm 0.8$ & $0.4 \pm 0.0$ \\
\hline
\end{tabular}

Ratios of low-molecular-weight proteins to high-molecular-weight MAPs were determined by densitometry of electrophoretic gels (Vallee and Davis, 1983). Data represent the average of 8-11 samples each for calf brain MAP 1A and MAP 1B, and 2 samples each for rat MAP 1A and MAP 1B. The molecular weight of the MAP 1 polypeptides was assumed to be $350 \mathrm{kDa}$. 


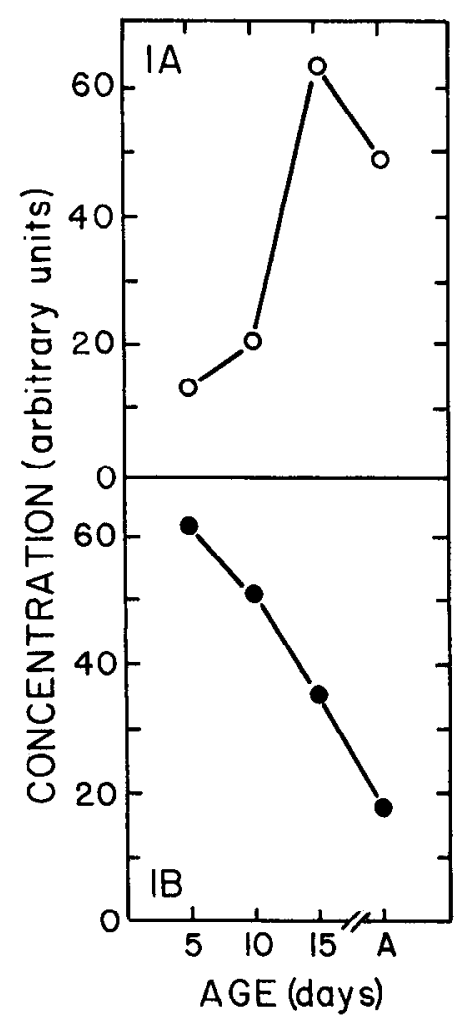

Figure 4. Opposite changes in MAP 1A and MAP 1B concentration with rat brain development. Whole brain tissue was dissolved and boiled for $5 \mathrm{~min}$ in electrophoresis sample buffer containing 6\% SDS. Equal amounts of protein from a series of ages after birth were subjected to electrophoresis on a $6 \%$ polyacrylamide gel, transferred to nitrocellulose, and reacted with either anti-MAP $1 \mathrm{~A}$ ( $1 \mathrm{~A}$, antibody MAP 1A-2) or antiMAP $1 B(1 B$, antibody MAP $1 B-4)$. The reaction product was quantitated by densitometry.

the MAP 1 species, proteolytic degradation of microtubule proteins was performed. The light chains were resistant to chymotrypsin (Fig. 3, Amido black lane 2) and continued to cosediment with microtubules following degradation of the highmolecular-weight MAP 1 bands (Fig. 3, Amido black lane 4). In addition to the light chains, a number of additional microtubule binding polypeptides were seen. These included a pair of fragments $\left(M_{r}\right.$ 32,000 and 34,000) generated from MAP 2 (Vallee, 1980) and a fragment of $M_{r}$ 120,000. This fragment, which we find to be resistant to further proteolysis, was judged to derive from MAP $1 \mathrm{~B}$ on the basis of immunoblotting with anti-MAP 1B antibodies (Fig. 3, blot). Extraction of the microtubules with $0.35 \mathrm{M} \mathrm{NaCl}$, which releases the MAPs, revealed the presence of an additional fragment of $M_{r} 60,000$ (Fig. 3, Amido black lane 5). Although none of the monoclonal antibodies recognized this fragment, it appears to derive from MAP 1A. It is not seen in digests of purified MAP 2 (Vallee, 1980), nor is it recognized by a monoclonal antibody to the MAP 2 microtubule binding fragments (R. Obar, J. Hyams, J. Dingus, and R. B. Vallee, unpublished observations). It is present at equal levels in digests of microtubules from both gray white matter. This rules out the possibility that it derives from MAP $1 \mathrm{~B}$, which is almost undetectable in gray matter microtubule preparations (Bloom et al., 1985a). The fragment can be seen only when separated from tubulin (Fig. 3, cf. Amido black lane 5 with lane 4), and, thus, it has remained undetected until now. The basis for this unusual electrophoretic behavior is not known.
Developmental expression of MAP 1A and MAP 1B

To compare the expression of MAP 1A and MAP 1B during brain development, whole brain tissue was dissolved in SDS sample buffer and examined by quantitative immunoblotting (Fig. 4). MAP $1 \mathrm{~B}$ was found to be most abundant in the newborn rat brain and to decline in amount with age. In contrast, MAP $1 \mathrm{~A}$ was present at lower concentration in the newborn and increased with age.

By immunofluorescence microscopy, we observed intense MAP 1B reactivity in newly forming axonal processes, apparently explaining the high concentration of MAP $1 \mathrm{~B}$ in early postnatal development. MAP 1A, on the other hand, was found to rise in concentration during development in a number of cellular structures. In our analysis, particular emphasis has been placed on regions in which extensive postnatal development of axonal processes is known to occur, to test whether the presence of MAP $1 \mathrm{~B}$ is generally associated with axonal development. The regions of interest were the cerebellum, where parallel fibers are laid down through at least P20; the olfactory bulb, where olfactory nerve fibers continue to develop after birth and even into adulthood; the corticospinal tract, where the invasion of neocortical efferent fibers into the brain stem and spinal cord can be followed almost entirely after birth; and the hippocampus, where the mossy fibers of the dentate gyrus invade subfields of the hippocampus proper after birth and apparently into adulthood (see below). These data are described region by region below.

\section{Cerebellum}

$M A P 1 B$. The most prominent staining at P5 is of the molecular layer and of the deep external granule layer (Fig. 5). A decreasing gradient of staining across the molccular laycr was apparent by P10, with the brightest labeling still occurring at the border between the external granule layer and the superficial molecular layer. By P20, intense staining occurred only in the external granule layer. The intense staining in the superficial layers of the cerebellar cortex corresponds to the position of premigratory, postmitotic granule cells whose parallel fiber axons are just beginning to extend from the parent cell body horizontally across the molecular layer. The decreasing intensity of staining with age and at deeper regions of the molecular layer is indicative of a decrease in the concentration of MAP $1 B$ with maturation of the granule cell axons. We also note intense staining of descending granule cell somata and their leading processes even as they descend deeply into the internal granule layer (Fig. 5).

P5-P10 Purkinje cell dendrites and somata and Bergmann glia appear virtually negative for MAP $1 \mathrm{~B}$ against the more intensely staining background of the parallel fibers in the molecular laver. Beginning at P20 and by the adult stage, however, moderate staining of the Purkinje cell dendrites and somata can be seen (Figs. 5D, 13), as well as moderate staining of the parallel fibers of the granule cells (Bloom et al., 1985a).

$M A P 1 A$. The somata and proximal dendritic segments of Purkinje cells are prominently stained with anti-MAP 1A at P5 and throughout their development (Fig. 6). The distal dendritic segments are not immunoreactive until P20. The molecular layer itself becomes more prominently and rather uniformly labeled by $\mathrm{P} 10$, showing a homogeneous and dense pattern consistent with the staining of bundles of parallel fibers (Fig. 6). However, this staining eventually disappears by adulthood (Bloom et al., 1984). Some weak staining of the deep external 

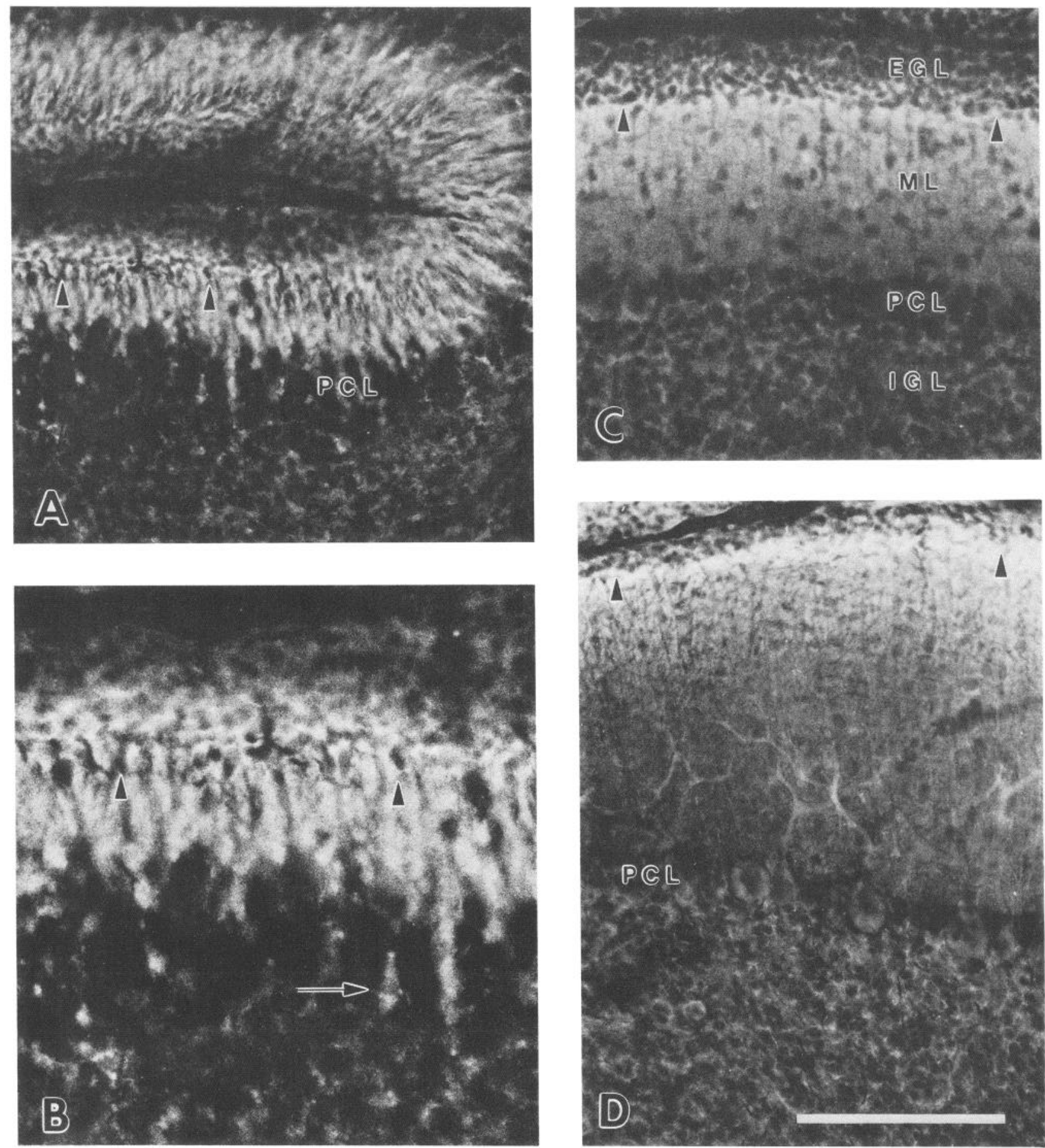

Figure 5. Anti-MAP 1B-4 immunoreactivity in the cerebellum at $\mathrm{P} 5(A, B), \mathrm{P} 10(C)$, and $\mathrm{P} 20(D)$, as seen in sagittal section. Arrowheads indicate the border between the deep, premigratory zone of the external granule layer $(E G L)$ and the superficial part of the molecular layer $(M L)$. Panel $B$ shows a magnified view of a portion of $A$; the arrowheads in $A$ correspond to the position of the arrowheads in $B$. The arrow in $B$ points to a labeled granule cell near the end of its migration positioned just deep to the unlabeled profiles of 2 Purkinje cells. Abbreviations: $P C L$, Purkinje cell layer; $I G L$, internal granule layer. Scale bar: $100 \mu \mathrm{m}$ for $A, C$, and $D ; 58 \mu \mathrm{m}$ for $B$.

granule layer is occasionally seen. However, this does not appear to be associated with a gradient of staining in the molecular layer as we see with MAP 1B.

\section{Olfactory bulb}

$M A P 1 B$. One of the most intensely stained features of the olfactory bulb at P0 is the olfactory nerve layer (Fig. 7). This staining persists into adulthood (Figs. 7, 13). The staining of olfactory nerve axons never appears to extend appreciably into the terminal regions within the glomeruli. At P0, an additional intense, deeply situated band of labeling can also be seen, corresponding to the mitral body layer (Fig. 7). Immunoreactivity appears to be localized between, rather than within, mitral cell somata, probably corresponding to staining of the proximal ax- 

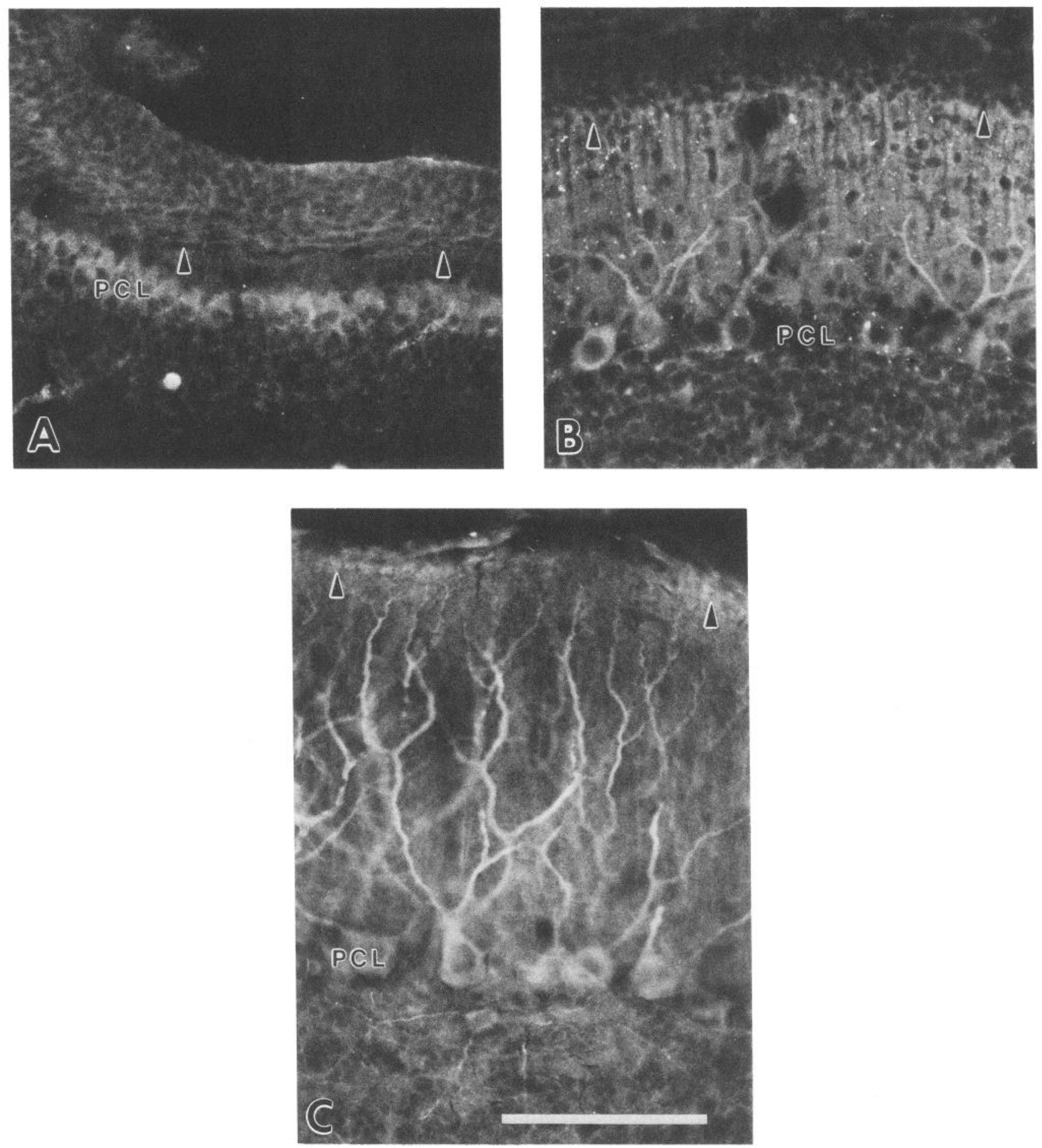

Figure 6. Anti-MAP 1A-1 immunoreactivity in the cerebellum at P5 (A), P10 (B), and P20 (C), as seen in sagittal section. Arrowheads indicate the border between the deep, premigratory zone of the external granule layer and the superficial part of the molecular layer. Abbreviations are as in Figure 5. Scale bar, $100 \mu \mathrm{m}$.

onal segments of these cells (see Hinds and Ruffett, 1973). Beginning at P7, the somata and dendrites of olfactory bulb principal and intrinsic neurons, including mitral, tufted, and granule cells, among others, become stained with anti-MAP 1B.

$M A P$ 1A. The olfactory nerve layer remains unstained throughout development (Fig. 8), in direct contrast to persistent MAP 1B staining of the olfactory nerve. However, from P0 onward, the somata and dendritic processes of all principal and intrinsic neurons are prominently labeled, particularly where these processes converge in the external plexiform and glomerular layers (Fig. 8). The staining of somata and dendrites is comparable to that seen with anti-MAP 1B at P7 and older, although the anti-MAP 1A staining is more extensive, involving more cellular profiles and processes within the bulb. 

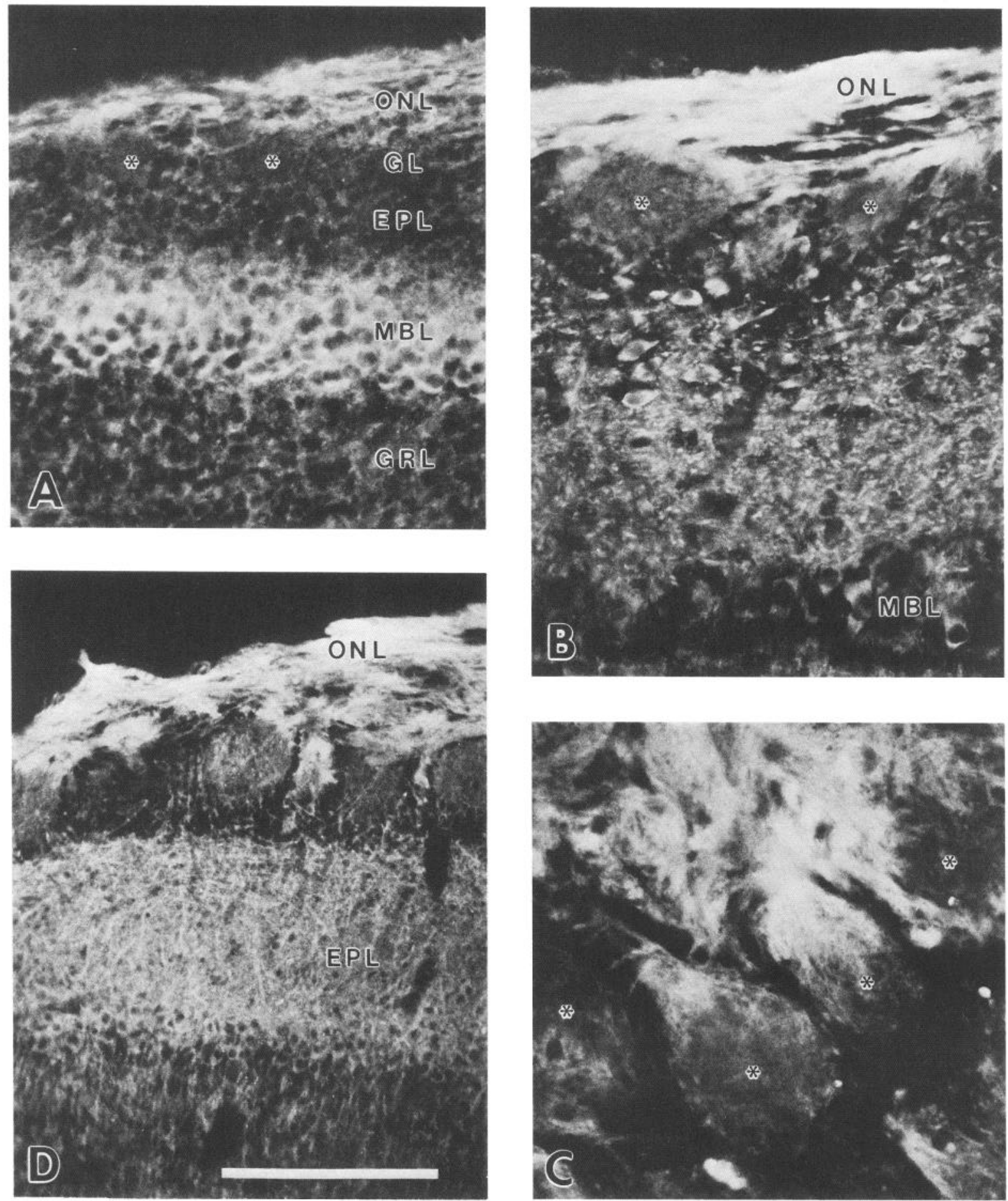

Figure 7. Anti-MAP 1B-4 immunoreactivity in the main olfactory bulb at P0 (A), P7 (B), P10 (C), and P20 (D), as seen in sagittal section. Asterisks indicate the location of individual glomeruli in the glomerular layer $(G L)$. Abbreviations: $O N L$, olfactory nerve layer; $E P L$, external plexiform layer; $M B L$, mitral body layer; $G R L$, granule layer. Scale bar: $100 \mu \mathrm{m}$ for $A-C, 250 \mu \mathrm{m}$ for $D$.

\section{Corticospinal tract}

$M A P 1 B$. At $\mathrm{P} 0$ the corpus callosum is intensely labeled by antiMAP $1 \mathrm{~B}$, and moderate staining of the spinal cord dorsal funiculus is seen (Fig. 9A). However, by P7-10 (Fig. 9B), intense staining of the dorsal funiculus of the cervical spinal cord and the corticospinal tract of the medulla (Fig. 9C) is observed, corresponding to the time of arrival of the corticospinal fibers (e.g., Schreyer and Jones, 1982). By P20 and into adulthood, MAP 1B immunoreactivity is no longer found associated with corticospinal tract axons in either the medulla or cervical spinal cord (Figs. 9D, 13).

MAP 1A. There is negligible staining of the corticospinal tract, including myelencephalic and spinal components of corticofugal 

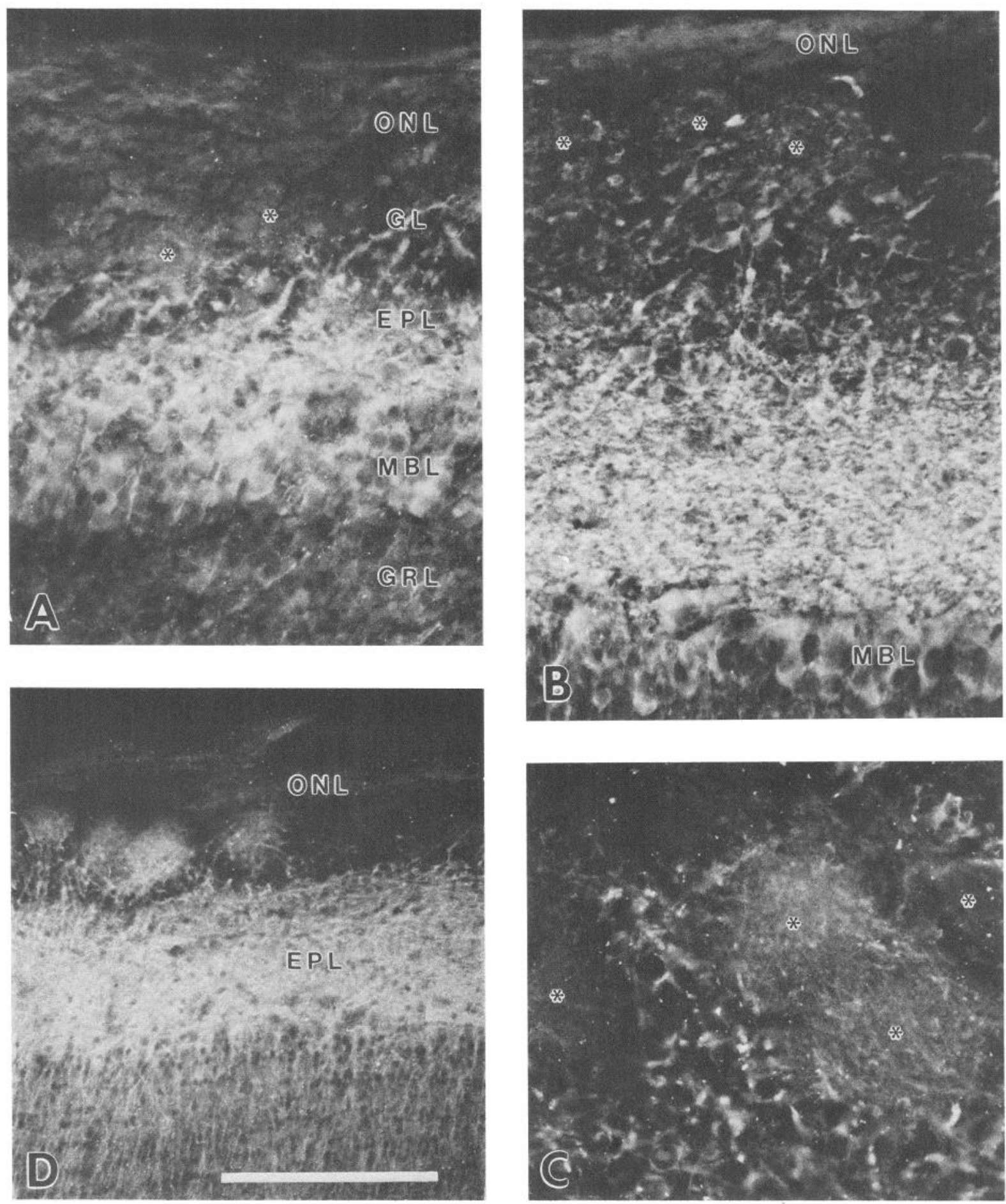

Figure 8. Anti-MAP 1A-1 immunoreactivity in the main olfactory bulb at P0 (A), P7 (B), P10 (C), and P20 (D), as seen in sagittal section. Asterisks and abbreviations are as in Figure 7. Scale bar: $100 \mu \mathrm{m}$ for $A-C, 250 \mu \mathrm{m}$ for $D$.

fibers, by anti-MAP $1 \mathrm{~A}$ at P0-7 (Fig. 10). By P10, there is more moderate labeling of fibers, e.g., in the ventral brain stem, together with cells embedded within the corticospinal tract which may be developing oligodendrocytes.

\section{Hippocampus (CA3 field)}

$M A P 1 B$. From P5 onward, there is prominent staining of mossy fiber axons and terminal fields within the CA3 field of the hip- pocampus (Fig. 11). This expression persists into adulthood (see Fig. 13). There is no apparent staining of the somata and dendrites of CA3 pyramidal cells until P20. Beginning at that point and in the adult, the stained mossy fibers and pyramidal cell dendrites are intermingled.

$M A P 1 A$. At all ages, the somata and dendrites of CA3 pyramidal cells are lightly stained (Fig. 12). There is no apparent staining of mossy fiber axons. 

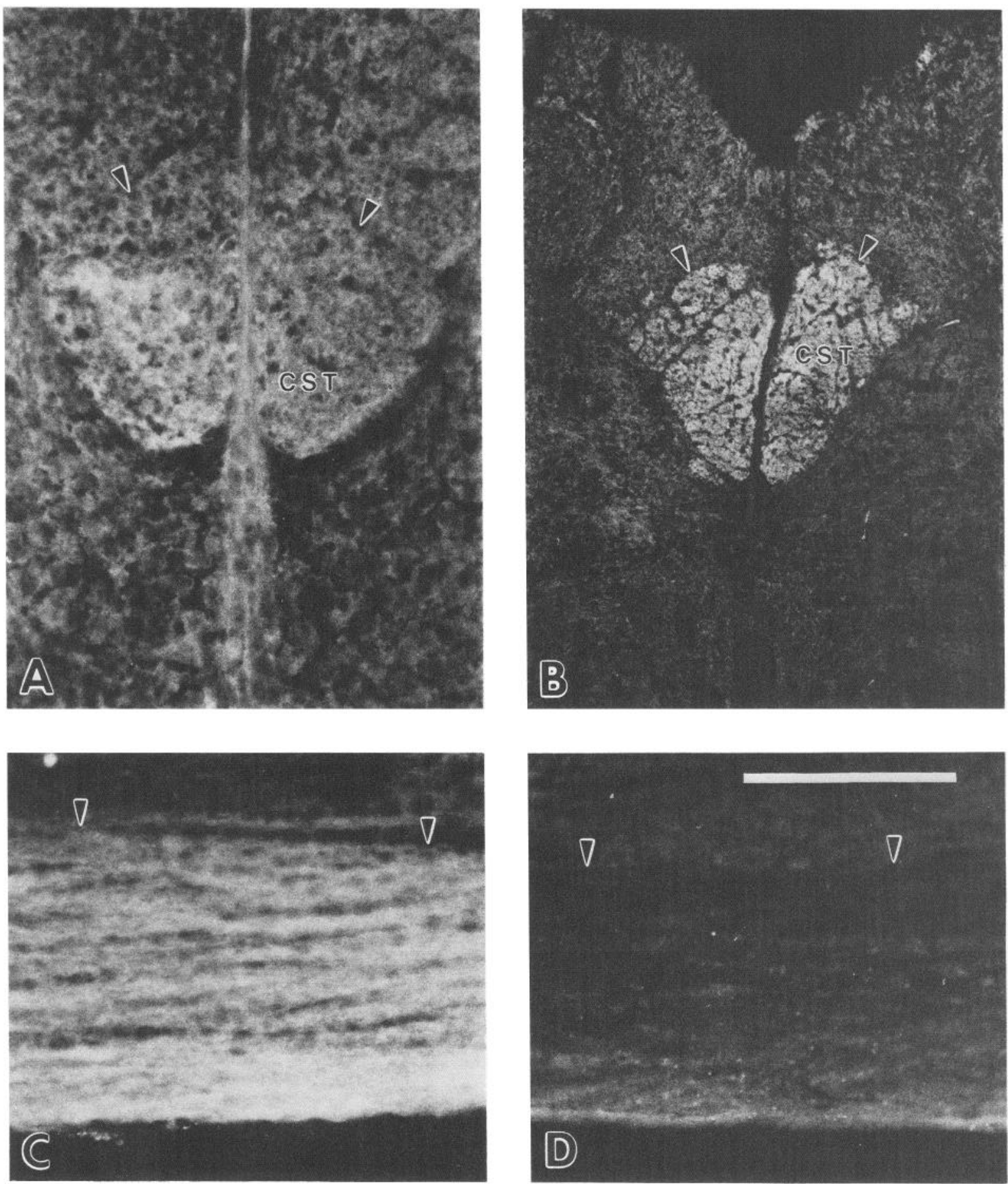

Figure 9. Anti-MAP 1B-4 immunoreactivity in the cervical spinal cord at $\mathrm{P} 0(A)$ and P7 $(B)$ and in the ventral medulla at P10 $(C)$ and P20 $(D)$. Panels $A$ and $B$ display the cervical corticospinal tract $(C S T)$ in coronal section, where it lies within the ventral aspect of the dorsal funiculus, whereas $C$ and $D$ display the medullary CST in saggital section at the level of the inferior olive. Arrowheads mark the dorsal boundary of the CST. Scale bar: $100 \mu \mathrm{m}$ for $A$ and $C, 250 \mu \mathrm{m}$ for $B$ and $D$.

\section{Distribution of a phospho-MAP 1 epitope}

One of the antibodies raised against MAP 1B, "MAP 1B-3," was found to recognize a phosphorylated epitope common to MAP 1B and MAP 1A (Luca et al., 1986). Immunoblotting of young brain tissue indicated that MAP 1A and MAP 1B were the only proteins recognized. However, in mature brain, high- and middle-molecular-weight neurofilament polypeptides were also intensely labeled. This made it difficult to determine the distribution of the phospho-MAP 1 epitope in mature brain. However, because the phosphorylated neurofilament antigens do not appear until relatively late in development (Shaw and Weber, 1982; Shaw et al., 1986), the distribution of phosphoMAP 1 immunoreactivity can be discerned in immature brain. 

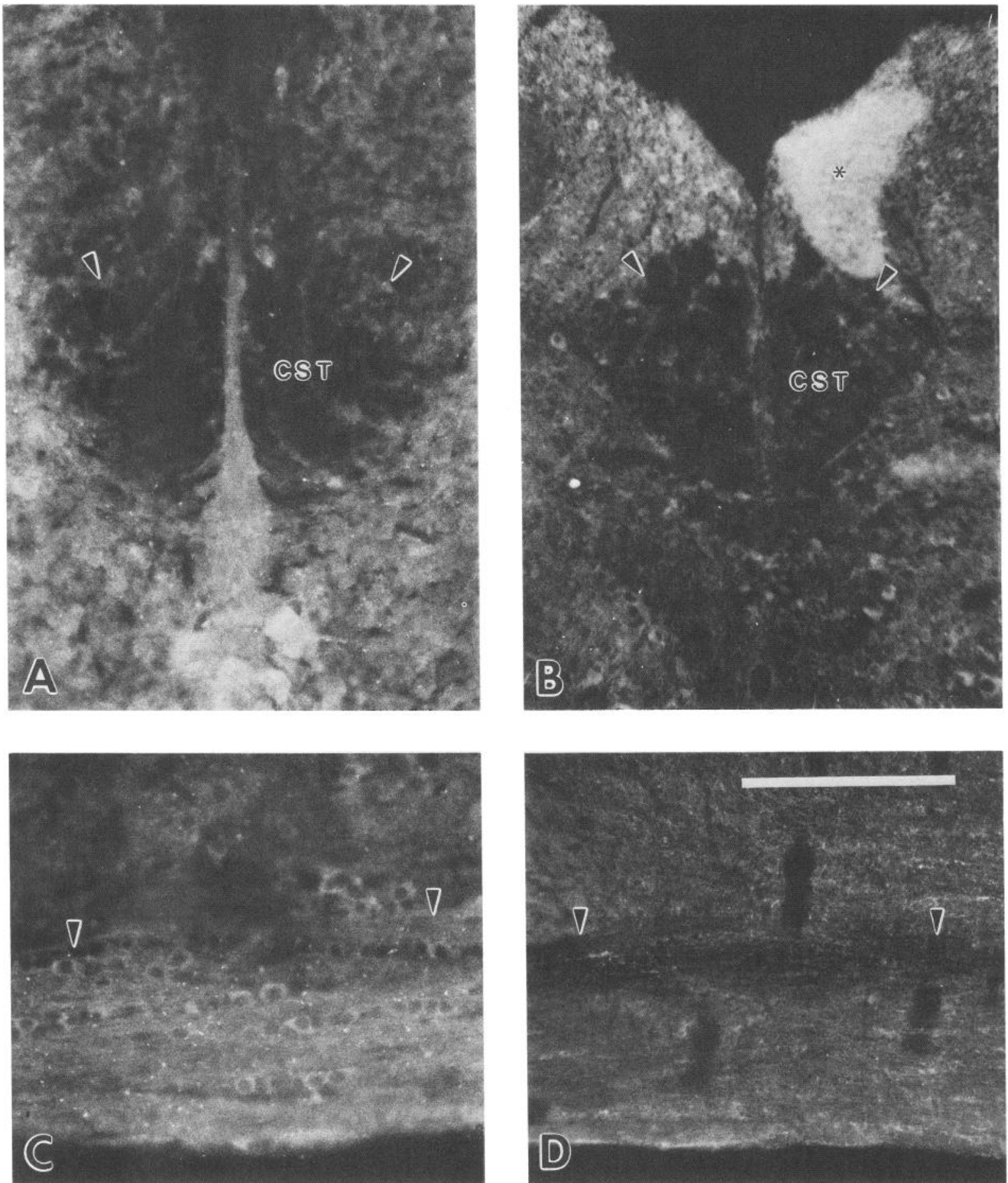

Figure 10. Anti-MAP 1A-1 immunoreactivity in the cervical spinal cord at $\mathrm{P} 0(A)$ and $\mathrm{P} 7(B)$ and in the ventral medulla at P10 $(C)$ and $\mathrm{P} 20$ $(D)$. Conventions for display of the panels and use of symbols are as in Figure 9 . The asterisk marks a tissue artifact. Scale bar: $100 \mu \mathrm{m}$ for $A$ and $C ; 250 \mu \mathrm{m}$ for $B$ and $D$.

We focused our analysis on the cerebellar cortex, where neurofilaments are known to be abundant in basket cell axons and absent from parallel fibers and Purkinje cell dendrites and somata (Sternberger and Sternberger, 1983; Shaw et al., 1986).

Figure 14 shows the immunofluorescence pattern observed with the anti-phospho-MAP 1 antibody in the cerebellum as a function of developmental stage. Early in development (P5-10;
Fig. 14A), the pattern of reactivity is indistinguishable from that of the other anti-MAP 1B antibodies (Fig. 5), with intense staining observed in the external granule cell layer and in the more superficial region of the molecular layer. Staining of dendritic processes in the molecular layer characteristic of the anti-MAP $1 \mathrm{~A}$ antibodies is not observed. Thus, it appears that MAP 1B in developing axons contains the MAP 1B-3 epitope in the 

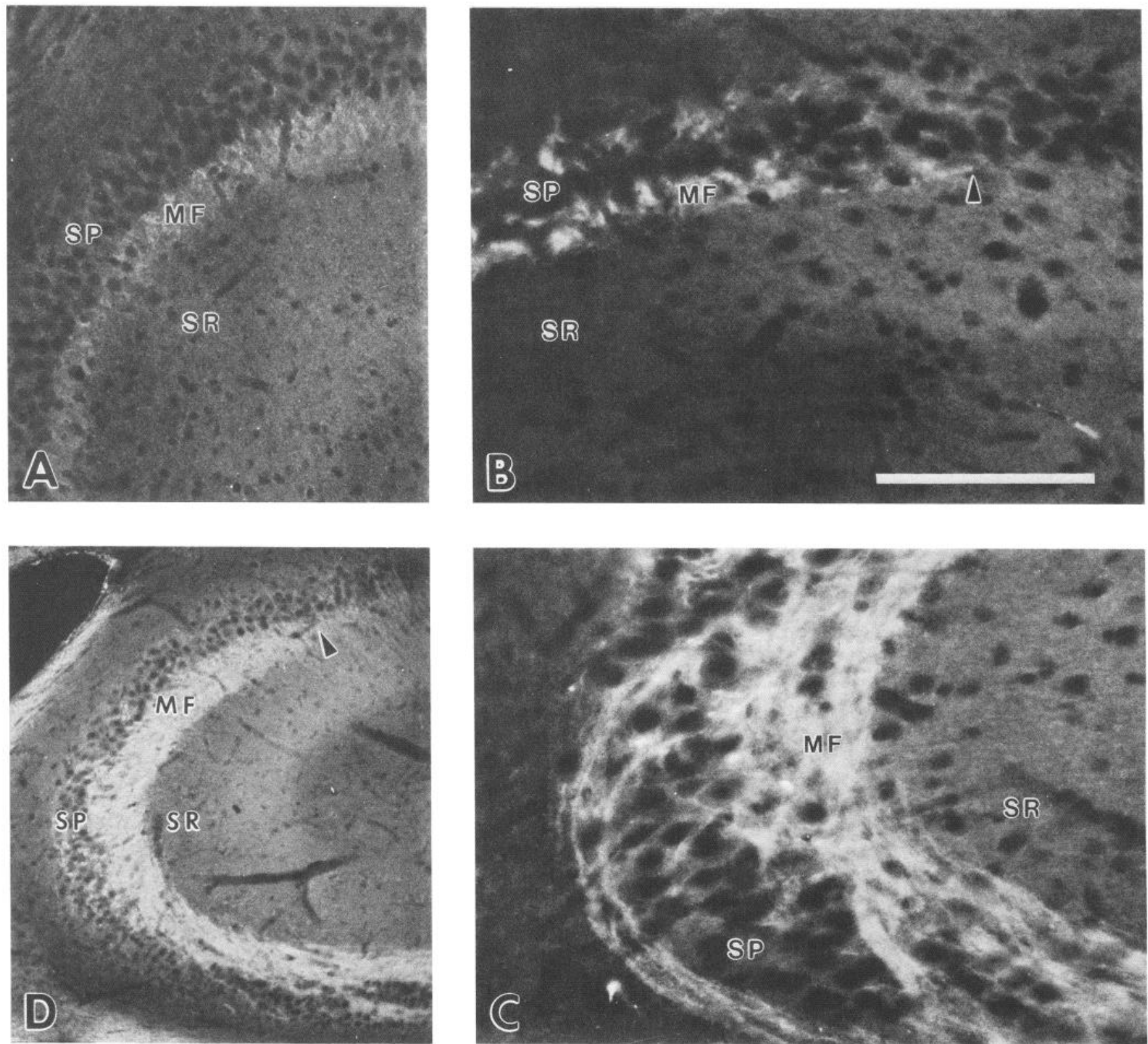

Figure 11. Anti-MAP 1B-4 immunoreactivity in the dorsal hippocampus at P5 $(A), \mathrm{P} 10(B, C)$, and $\mathrm{P} 20(D)$, as seen in sagittal section. The arrowhead marks the extent of mossy fiber $(M F)$ innervation of pyramidal cell dendrites within hippocampal field CA3. Abbreviations: $S P$, stratum pyramidale; $S R$, stratum radiatum. Scale bar: $160 \mu \mathrm{m}$ for $A, 100 \mu \mathrm{m}$ for $B$ and $C, 400 \mu \mathrm{m}$ for $D$.

phosphorylated form. On the other hand, MAP 1A in developing dendrites must contain the epitope in an unphosphorylated form, or the epitope must be masked.

Prominent staining of the premigratory zone of the external granule layer is still evident by P20, along with light staining of more mature parallel fibers across the molecular layer (Fig. 14B). This is the pattern characteristic of the other anti-MAP 1B antibodies (Fig. 5). Because neurofilaments are absent from both mature and immature parallel fibers (Shaw and Weber, 1982; Shaw et al., 1986), the observed staining by antibody MAP 1B-3 offers evidence that MAP 1B is in the phosphorylated form in these processes throughout their development. Purkinje cell dendrites and somata are unstained by antibody MAP 1B-3. This is despite the clear presence of both MAP 1A and MAP
1B (Figs. 5, 6), suggesting that both proteins are in the unphosphorylated form in these structures. The most striking staining observed at this stage is that of the basket cell axons around the Purkinje cell bodies (Fig. 14) and of large-caliber axons in the white matter. This pattern is characteristic of anti-phospho neurofilament antibodies (Sternberger and Sternberger, 1983; Shaw et al., 1986).

In the adult, the most prominent staining with anti-MAP 1B-3 is of basket cell axons and large-caliber axon bundles in the white matter (Fig. 14C), a pattern characteristic of antiphospho neurofilament antibodies as noted above. Light staining of some dendrites of Purkinje cells can also be seen in some sections (not shown). These structures are not stained with antiphospho neurofilament antibodies (Shaw et al., 1986). 

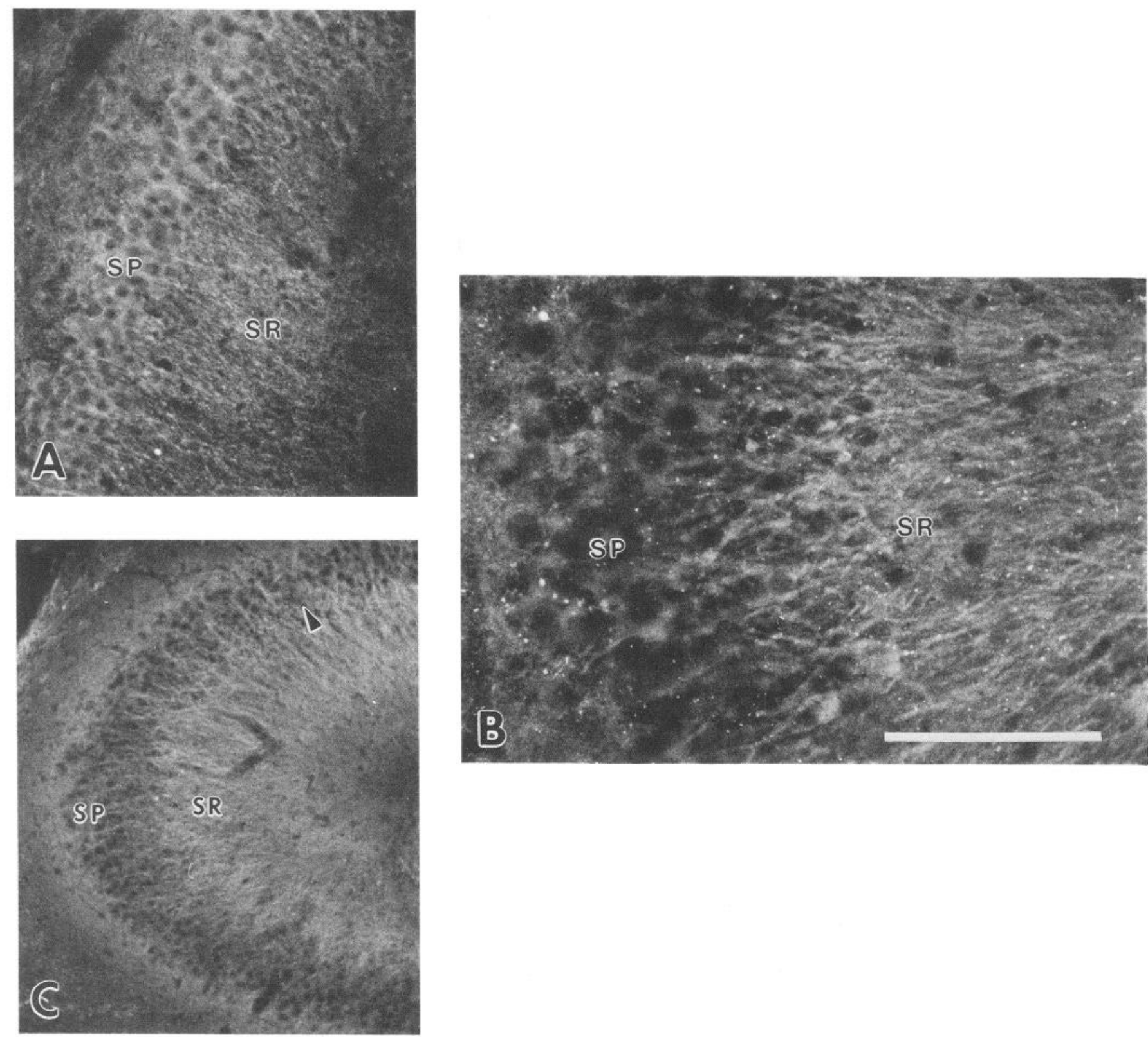

Figure 12. Anti-MAP 1A-1 immunoreactivity in the dorsal hippocampus at P5 (A), P10 (B), and P20 (C), as seen in sagittal section. The arrowhead in $C$ marks the approximate extent of unlabeled MF innervation within hippocampal field CA3. Abbreviations are as in Figure 11. Scale bar: 160 $\mu \mathrm{m}$ for $A, 100 \mu \mathrm{m}$ for $B, 400 \mu \mathrm{m}$ for $C$.

\section{Discussion}

Structure of MAP $1 A$ and MAP $1 B$

Earlier work indicated a general lack of cross-reactivity between MAP 1A and MAP 1B, clear differences in their peptide maps, and a significant difference in their apparent affinities for microtubules (Bloom et al., 1984, 1985a; Vallee and Luca, 1985). In addition, hybridization with a cDNA probe corresponding to a portion of what may be MAP 1B revealed no evidence for a related gene (Lewis et al., 1986). Nonetheless, our biochemical results indicate that MAP 1A and MAP 1B are, in fact, structurally related, as revealed by their pattern of associated lightchain subunits (Figs. 1, 2). Work is currently under way in our laboratory to examine the possibility of common light-chain binding sequences in MAP 1A and MAP 1B using molecular cloning techniques (Hammarback et al., 1989).
We have uncovered further differences between the 2 proteins as well. We identify different microtubule binding fragments generated from the 2 proteins (Fig. 3). We also note that MAP 1B contains little or no light chain 2 (Figs. 1, 2). We have observed this as a consistent feature of MAP 1B immunoprecipitated by several different antibodies, from both gray and white matter (unpublished observations), and from 2 different animal species (Figs. 1, 2; Table 1). This observation is entirely consistent with our earlier finding that the ratio of light chain 1:light chain 2 was greater in white matter microtubules than in gray matter microtubules (Vallee and Davis, 1983), in that the white matter microtubules always contain substantially more MAP 1B than the gray matter microtubules. Why MAP 1A and MAP 1B differ in this respect is uncertain, though our finding of trace levels of light chain 2 in MAP 1B immunoprecipitates suggests that binding is possible but not favored. Whatever the 

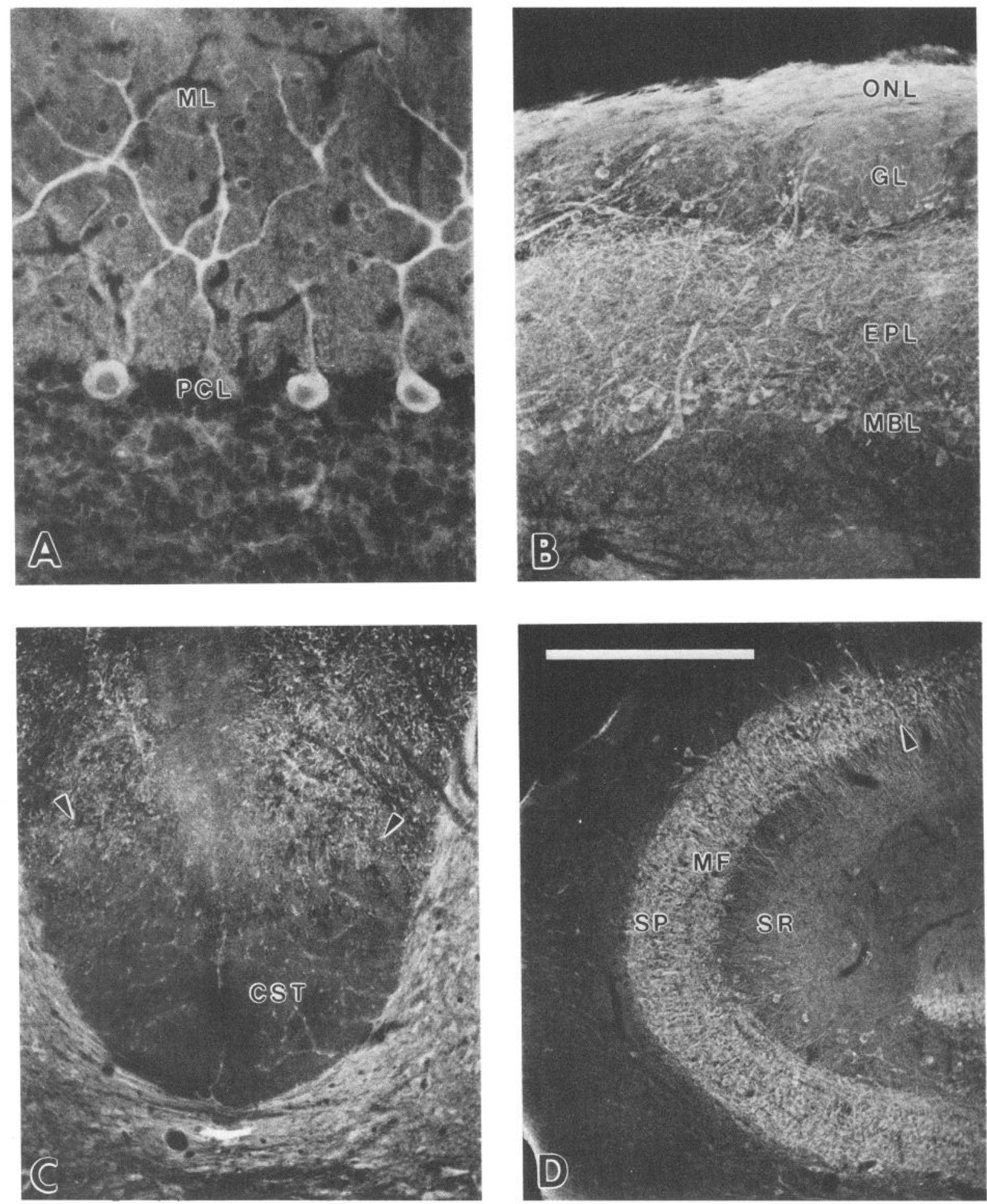

Figure 13. Anti-MAP 1B-4 immunoreactivity in the cerebellum $(A)$, main olfactory bulb $(B)$, cervical spinal cord $(C)$, and hippocampus $(D)$ of the adult. Abbreviations and arrowheads are as in previous figures. Scale bar: $100 \mu \mathrm{m}$ for $A, 160 \mu \mathrm{m}$ for $B, 400 \mu \mathrm{m}$ for $C$ and $D$.

cause, the light chain compositions of MAP 1A and MAP 1B serve as distinctive biochemical signatures for the 2 proteins. This should be useful in their identification in mammalian systems, though we note that in preliminary immunoprecipitation experiments with chicken brain using antibodies "MAP 1A-2," "MAP 1A-4," and "MAP 1B-2," both MAP 1A and MAP 1B contained light chains 1 and 3 , with no light chain 2 detectable
(L. McKerracher, unpublished observations). We do not yet know if this is evidence that light chains 1 and 2 are functionally interchangeable, or whether light chain 2 is subject to proteolytic degradation in the chicken.

Our data suggest that for both MAPs, the light chains are situated at the microtubule binding end of the molecule (Fig. 15). This conclusion is based on the persistence of the light 

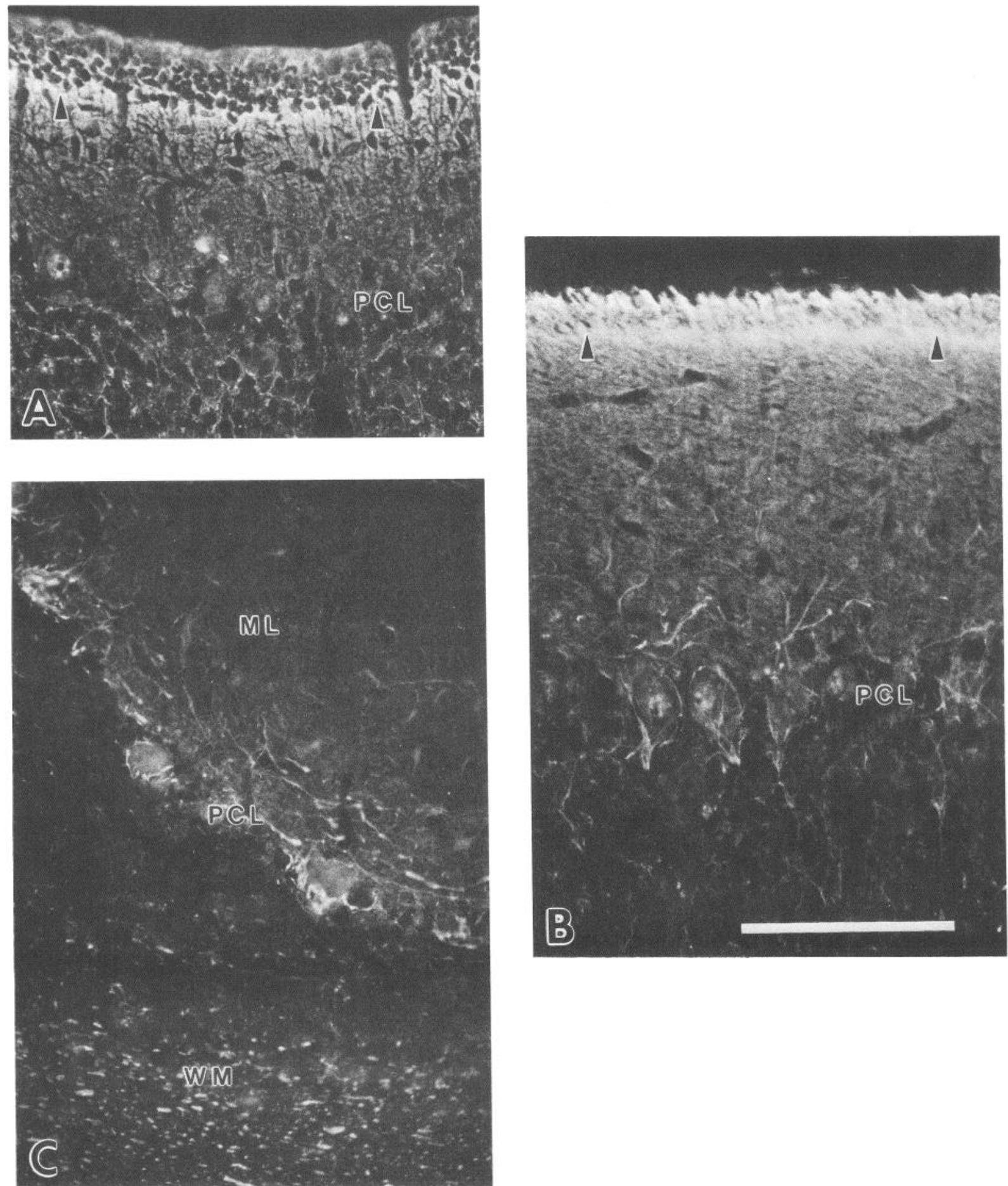

Figure 14. Anti-MAP 1B-3 immunoreactivity in the cerebellum at P7 $(A), \mathrm{P} 20(B)$, and in the adult $(C)$. Arrowheads in $A$ and $B$ indicate the border between the deep, premigratory zone of the external granule layer and the superficial part of the molecular layer $(M L)$. Abbreviations: $P C L$, Purkinje cell layer; $W M$, white matter deep to the cerebellar cortex. Scale bar, $100 \mu \mathrm{m}$.

chains in microtubule pellets following chymotryptic digestion (Fig. 3) along with microtubule binding fragments of MAP 1A and MAP 1B. Preliminary evidence has indicated that purified light chains may bind to microtubules directly (R. Obar, unpublished observations), suggesting that these polypeptides could be directly involved in microtubule binding. They could therefore be responsible for differences in binding affinity to microtubules (Bloom et al., 1985a) and might influence the relative microtubule assembly-promoting activity of the 2 proteins. According to our model (Fig. 15), MAP 1A and MAP 1B are structurally different from MAP 2, which has a simpler microtubule binding domain (Vallee, 1980; Lewis et al., 1988).

Our data are consistent with those obtained with a monoclonal antibody to light chain 1 (Kuznetsov et al., 1986; Kuznetsov and Gelfand, 1987). That antibody immunoprecipitated 2 high-molecular-weight MAPs, though their identity was un- 


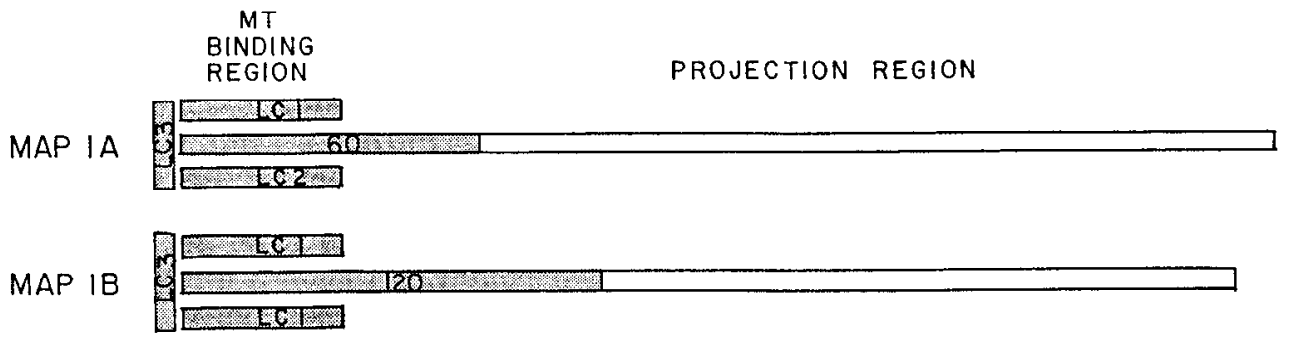

Figure 15. Schematic representation of MAP 1A and MAP $1 \mathrm{~B}$ molecules. Each molecule is shown as a complex of a heavy chain and several light chains associated with the microtubule binding region of the molecule. We identify microtubule binding fragments of $M_{r}$ 120,000 for MAP $1 \mathrm{~B}$ and $M_{r} 60,000$ for MAP 1A. certain. Digestion of the MAPs with chymotrypsin resulted in the production of a fragment of $M_{r} 120,000$, the same as our MAP 1B fragment, and this species also co-immunoprecipitated with light chain 1 . Our $M_{r} 60,000$ MAP 1A fragment was not observed in that study. This is not surprising in view of our observation that it is less stable to further digestion than the $M_{r}$ 120,000 MAP 1B fragment.

\section{Differential distribution in the CNS}

In previous work we found that MAP 1A and MAP 1B were both more widely distributed than MAP 2, which is largely restricted to neuronal dendrites. Some differences in the relative intensity of anti-MAP $1 \mathrm{~A}$ and anti-MAP $1 \mathrm{~B}$ staining could be seen in the adult cerebellum, but both proteins could be found throughout the neuron and in non-neuronal cells as well. Bccause MAP 2 is largely absent in axons, we proposed that MAP $1 \mathrm{~A}$ and MAP 1B were the major structural components of the axonal cytoskeleton observed by freeze-etch electron microscopy (Hirokawa et al., 1985).

We find here that the 2 proteins have a more or less complementary distribution during development (Fig. 4). MAP 1B is much more abundant in the newborn rat brain than in the adult; the reverse is true for MAP 1A. The greater abundance of MAP $1 \mathrm{~B}$ in the neonate is associated with the intense labeling of newly forming axonal processes by anti-MAP 1B antibodies during the first weeks of life, which diminishes as the axons mature. The increasing concentration of MAP 1A with development corresponds to the expansion of mature dendritic arbors in which this protein is particularly abundant.

The precise schedule of MAP $1 \mathrm{~B}$ expression is region-specific. For example, in the cerebellum from P0 through P20 these antibodies intensely stain the premigratory zone of the external granule layer and the superficial part of the molecular layer (Fig. 5), where the horizontal outgrowth of the granule cell parallel fiber axons takes place (Altman, 1972). In the olfactory bulb, olfactory nerve axons are prominently stained by MAP $1 \mathrm{~B}$ antibodies at the earliest age examined (P0). Staining persists throughout the postnatal period and into adulthood. (Figs. 7 , 13), consistent with the continuing postnatal growth of these axons (Graziadei and Monti-Graziadei, 1978; Farbman and Squinto, 1985). In the corticospinal tract, staining is moderate at $\mathrm{P} 0$ and then peaks in intensity in the medulla and cervical spinal cord at P5-7 (Fig. 9), the age of peak axonal growth through these regions (Donatelle, 1977; Schreyer and Jones, 1982). Beyond this period of peak growth, MAP 1B immunoreactivity in the corticospinal tract is undetectable (Figs. 9, 13).

The staining pattern in the hippocampus with anti-MAP 1B antibodies is of particular interest. Mossy fiber axons in the CA3 region begin to show staining by MAP 1B antibodies at P5, but this immunoreactivity increases dramatically in intensity through P20 and persists in the adult (Figs. 11,13). The staining during postnatal development is consistent with the known time course of appearance of mossy fibers during this period (Gaarskjaer, 1985). The staining of the adult mossy fibers by anti-MAP 1B antibodies reported here supports claims of the continued generation of granule cells in the adult dentate gyrus. The number of granule cells in this region has been reported to increase in the adult due to continued cell division (Bayer, 1982; Crespo et al., 1986). This would, presumably, result in the generation of new mossy fibers, conceivably at a rate of 1000 a day throughout life, assuming one axon per new granule cell (Bayer, 1982). However, we are unaware of any studies that have attempted to demonstrate directly that such axonal growth in the adult actually takes place. Our data thus provide the first evidence that such growth does, indeed, occur and indicate that immunocytochemical staining with anti-MAP $1 \mathrm{~B}$ antibodies offers a means for detecting the newly forming processes.

The overall decline in MAP $1 \mathrm{~B}$ expression with age is associated with a reduction in the intensity of expression in axonal processes generally, with the exception of the olfactory nerve and mossy fiber axons, and the emergence of a moderate level of expression in dendrites and somata throughout the CNS.

In contrast to the distribution observed for MAP $1 \mathrm{~B}$ in the neonatal CNS, MAP 1A is associated with neuronal somata and only the proximal portions of dendrites (e.g., Fig. 6; cf. Cambray-Deakin et al., 1987). With increasing age, MAP $1 \mathrm{~A}$ is found throughout the dendritic arbor and in many axonal processes (Bloom et al., 1984), although it appears to be only transiently expressed in the parallel fiber axons (Fig. 6; cf. Cambray-Deakin et al., 1987).

Thus, while our evidence indicates that MAP 1A and MAP $1 B$ are structurally related proteins, their developmental and spatial expression differ in many ways (summarized in Fig. 16). MAP $1 \mathrm{~B}$ is most prominently associated with developing axonal processes, which may be susceptible to some degree of structural and synaptic remodeling. In contrast, MAP $1 \mathrm{~A}$ is most prominently associated with the proximal segments of developing dendritic arbors, which we presume have a more stable configuration than the more distal, growing tips. We suggest that MAP $1 \mathrm{~A}$ may have a greater stabilizing effect on microtubules than MAP 1B, which would allow for more or less facility in cytoskeletal reorganization. In support of this notion is the observation that MAP $1 \mathrm{~B}$ alone among the several MAPs we have investigated copurified inefficiently with microtubules (Bloom et al., 1985a). This most likely reflects a lower affinity of MAP $1 \mathrm{~B}$ than MAP 1A or MAP 2 for microtubules, which should, in turn, imply a weaker ability to stabilize microtubules.

\section{Distribution of phosphorylated MAP 1}

In earlier work we found that one of our antibodies, MAP 1B3 , reacted with a phosphorylated epitope on both MAP $1 B$ and MAP 1A. This antibody also cross-reacts with a phosphorylated 


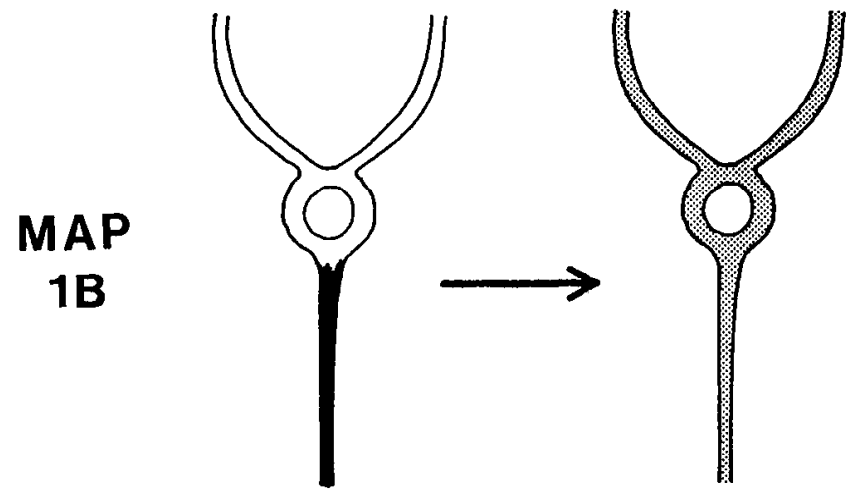

\section{developing}

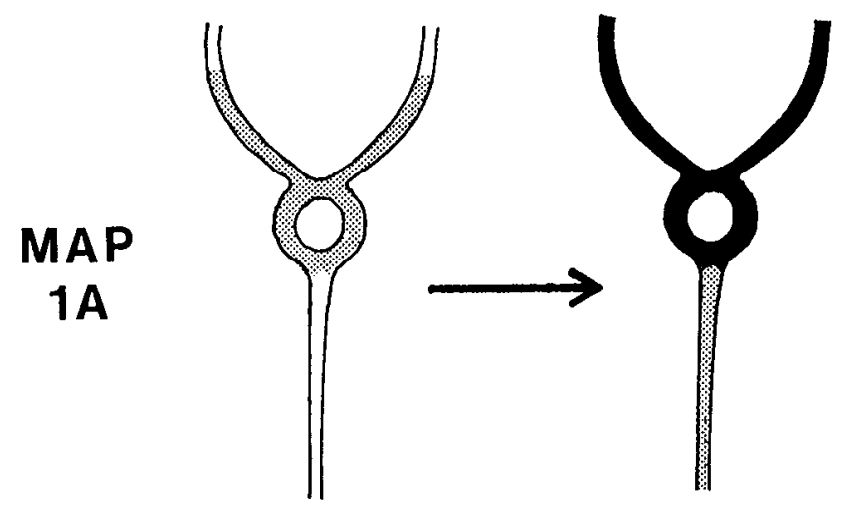

Figure 16. Summary diagram comparing immunoreactive patterns of MAP $1 B$ and MAP $1 A$ neuronal expression as a function of age. Each drawing depicts a neuronal cell soma with nucleus, 2 dendrites at the top, and a descending axon. For MAP 1B, intense expression restricted to the axon of a developing neuron gives way to more moderate expression in all compartments of the mature neuron, including the emergence of somatic and dendritic expression not found early in development. In contrast, for MAP 1A, moderate expression in the soma and the proximal segments of the dendrites of a developing neuron gives way in the mature neuron to more intense expression in the soma and entire dendritic tree and to the emergence of moderate expression in the axon.

epitope on the heavy- and middle-molecular-weight neurofilament polypeptides, which greatly complicates the analysis of the pattern of immunoreactivity observed in the adult rat. However, because the phosphorylated neurofilament antigens appear late in development (Shaw and Weber, 1982; Shaw et al., 1986), and the distribution of neurofilaments in cerebellar cortex is well documented (Sternberger and Sternberger, 1983; Shaw et al., 1986), it is possible to interpret the distribution of the phospho-form of MAP $1 \mathrm{~A}$ and MAP $1 \mathrm{~B}$ in the developing cerebellum (Fig. 14).

We find that our anti-phospho MAP 1 antibody stains ncwly forming parallel fiber axons in a pattern indistinguishable from that observed with the other anti-MAP $1 \mathrm{~B}$ antibodies (Figs. 5, 14). Since MAP 1A and neurofilaments are absent from these structures, we conclude that the pattern of immunoreactivity that we see is that of phospho-MAP 1B. In somata and dendritic processes of the newborn rat cerebellum, where we know MAP $1 \mathrm{~A}$ to be abundant and the neurofilaments and MAP 1B to be absent, no reactivity with the MAP 1B-3 antibody was seen.
Thus, MAP IA is in the nonphosphorylated form in developing dendrites. This pattern of distribution of the phosphorylated cpitope is the same as that reported for phosphorylated neurofilament epitopes in mature brain, which also are expressed in axons but not in dendrites or somata (Shaw et al., 1986). It is the converse of the distribution of a phosphorylated epitope on the tau MAPs (Papasozomenos and Binder, 1987).

In the more mature cerebellum (Fig. 14, $B, C$ ), the absence of staining of Purkinje cell somata and the rare light staining of Purkinje cell dendrites by anti-MAP 1B-3, despite their prominent staining by other anti-MAP $1 \mathrm{~A}$ and $1 \mathrm{~B}$ antibodies, further indicates that these structures contain unphosphorylated forms of these MAP 1 proteins. The prominent staining of basket cell and white matter axons with anti-MAP $1 \mathrm{~B}-3$, which is characteristic of anti-phospho-neurofilament immunoreactivity and is not seen with other anti-MAP 1 antibodies, is consistent with the documented cross-reactivity of this antibody with phosphorylated high- and middle-molecular-weight neurofilaments (Luca et al., 1986).

\section{Comparison with other antibodies}

The developmental changes in the pattern of immunoreactivity observed with our MAP 1 antibodies show similarities to, as well as differences from, those found with several other MAP antibodies. For example, monoclonal anti-"MAP 1" of Matus and colleagues (Bernhardt et al., 1985) shows an increase in overall staining intensity with age, consistent with its identification as MAP 1A (Matus, 1988). However, the regional staining pattern observed with this antibody differs from that seen with our anti-MAP 1A antibodies. For example, in the cerebellum, the anti-MAP 1 antibody shows an intense staining of parallel fiber axons in the cerebellar molecular layer that decreases with age, similar to the pattern seen with our anti-MAP 1B antibodies. The staining of Purkinje cell somata and dendrites seen with the anti-MAP 1 antibody (Bernhardt et al., 1985) is, on the other hand, essentially the pattern observed with our anti-MAP $1 \mathrm{~A}$ antibodies.

Likewise, monoclonal antibody G10 of Calvert and Anderton (1985; see also Calvert et al., 1987), which reacts with a MAP 1 protein from 2-d-old rat brain named "MAP 1X," stains only developing axons in the immature and mature brain. This pattern is similar to the intense immunoreactivity we observe in outgrowing axons with our anti-MAP 1B antibodies. However, it represents only a subset of the anti-MAP 1B staining pattern. Staining of adult mossy fibers with antibody G10 is weak, and more general staining of adult neurons and glia is not reported. Perhaps the G10 antibody recognizes an epitope of MAP 1B that is expressed only in outgrowing axons but is effectively masked otherwise (Calvert et. al., 1987).

A monoclonal antibody to a protein identified as "MAP 5" (Matus and Riederer, 1986; Riederer et al., 1986) reacts with a protein doublet, the heavier of which $(320 \mathrm{kDa})$ is similar in sizc to MAP 1B. The developmental staining pattern shows many similarities to that of MAP 1B since both are initially expressed in outgrowing axons and ultimately expressed in both axons and dendrites. We note that the immunoreactivity of Purkinje cell dendrites relative to parallel fibers in the molecular layer at P5-10 appears much more intense with the anti-MAP 5 antibody (Riederer et al., 1986) than what we have observed with anti-MAP 1B. Moreover, staining of hippocampal mossy fibers with anti-MAP $1 \mathrm{~B}$ persists into adulthood, whereas mossy 
fiber staining with the anti-MAP 5 antibody does not (Matus and Riederer, 1986). However, it is possible that these differences in staining pattern reflect differences in histochemical procedure rather than in epitope distribution.

In view of these differences, it is not clear how MAP $1 \mathrm{X}$ and MAP 5 are related to MAP $1 \mathrm{~A}$ and MAP $1 \mathrm{~B}$. It is possible that the antibodies used in the other studies recognized epitopes hidden at some developmental stage, or modified, for example, by phosphorylation. We have clearly found that an antibody directed at one phosphorylated epitope, MAP 1B-3, shows a number of differences in its pattern of immunoreactivity from our other anti-MAP 1 antibodies. One additional antibody of this class has now been documented (de Mey et al., 1987), and others may, indeed, be common. We note, in fact, that the antiphospho neurofilament antibody RT97 (Wood and Anderton, 1981) was observed to react with developing parallel fibers (Cambray-Deakin and Burgoyne, 1986), despite the absence of neurofilaments in these processes. This antibody appears to us to cross-react with higher-molecular-weight polypeptides in cerebellar homogenates (Cambray-Deakin and Burgoyne, 1986; see their figure 2), which could be MAP 1A and MAP $1 \mathrm{~B}$.

Because of these problems and the even greater diversity of results obtained using anti-MAP 1 antibodies outside of the nervous system (see introductory remarks), it will be important to understand these proteins at the molecular level. We have begun this process by showing that MAP $1 \mathrm{~A}$ and MAP $1 \mathrm{~B}$ are, in fact, related in higher order structures, and we have provided some structural criteria for their identification in general. This should provide a basis for on-going and future work directed at comparing these proteins at the primary sequence level.

Note added in proof: Dr. A. Matus has informed us that our MAP 1B-4 antibody recognizes a fusion protein encoded by a MAP 5 cDNA clone, indicating that MAP 5 is equivalent to or closely related to MAP $1 \mathrm{~B}$. He also found that anti-MAP $1 \mathrm{X}$ reacted with immunoprecipitated MAP 5, suggesting that MAP $1 \mathrm{X}$ is also equivalent to MAP $1 \mathrm{~B}$.

\section{References}

Altman, J. (1972) Postnatal development of the cerebellar cortex in the rat. I. The external germinal layer and the transitional molecular layer. J. Comp. Neurol. 145: 353-398.

Asai, D. J., W. C. Thompson, L. Wilson, C. F. Dresden, H. Schulman, and D. L. Purich (1985) Microtubule-associated proteins (MAPs): A monoclonal antibody to MAP 1 decorates microtubules in vitro but stains stress fibers and not microtubules in vivo. Proc. Natl. Acad. Sci. USA 82: 1434-1438.

Bayer, S. A. (1982) Changes in the total number of dentate granule cells in juvenile and adult rats: A correlated volumetric and $3 \mathrm{H}$ thymidine autoradiographic study. Exp. Brain Res. 46: 315-323.

Bernhardt, R., G. Huber, and A. Matus (1985) Differences in the developmental patterns of three microtubule-associated proteins in the rat cerebellum. J. Neurosci. 5: 977-991.

Binder, L. I., A. Frankfurter, H. Kim, A. Caceres, M. R. Payne, and L. I. Rebhun (1984) Heterogeneity of microtubule-associated protein-2 during rat brain development. Proc. Natl. Acad. Sci. USA 81: 56135617.

Blake, M. S., K. H. Johnston, G. J. Russell-Jones, and E. C. Gotschlich (1984) A rapid, sensitive method for detection of alkaline phosphatase conjugated anti-antibody on western blots. Anal. Biochem. 136: $175-179$.

Bloom, G. S., T. A. Schocnfeld, and R. B. Vallec (1984) Widespread distribution of the major polypeptide component of MAP 1 (Microtubule Associated Protein 1) in the nervous system. J. Cell Biol. 98: 320-330.

Bloom, G. S., F. C. Luca, and R. B. Vallee (1985a) Microtubule as- sociated protein 1B: Identification of a major component of the neuronal cytoskeleton. Proc. Natl. Acad. Sci. USA 82: 5404-5408.

Bloom, G. S., F. C. Luca, C. A. Collins, and R. B. Vallee (1985b) Use of multiple monoclonal antibodies for the characterization of the major microtubule associated protein in sea urchin eggs. Cell Motil. Cytoskel. 5: 431-446.

Bonifacino, J. S., R. D. Klausner, and I. V. Sandoval (1985) A widely distributed nuclear protein immunologically related to the microtubule-associated protein 1 (MAP-1) is associated with the mitotic spindle. Proc Natl. Acad. Sci. USA 82: 1146-1150.

Calvert, R., and B. H. Anderton (1985) A microtubule-associated protein (MAP1) which is expressed at elevated levels during development of the rat cerebellum. EMBO J. 4: 1171-1176.

Calvert, R. A., P. L. Woodhams, and B. H. Anderton (1987) Localization of an epitope of a microtubulc-associated protein $1 \mathrm{x}$ in outgrowing axons of the developing rat central nervous system. Neuroscience 23: 131-141.

Cambray-Deakin, M. A., and R. D. Burgoyne (1986) Transient expression of neurofilament-like (RT97) immunoreactivity in cerebellar granule cells. Dev. Brain Res. 28: 282-286.

Cambray-Deakin, M. A., K.-M. Norman, and R. D. Burgoyne (1987) Differentiation of the cerebellar granule cell: Expression of a synaptic vesicle protein and the microtubule-associated protein MAP 1A. Dev. Brain Res. 34: 1-7.

Crandall, J. E., M. Jacobson, and K. S. Kosik (1986) Ontogenesis of microtubule-associated protein 2 (MAP2) in embryonic mouse cortex. Dev. Brain Res. 28: 127-133.

Crespo, D., B. B. Stanfield, and W. M. Cowan (1986) Evidence that latc-gencratcd granulc cells do not simply replace earlier formed neurons in the rat dentate gyrus. Exp. Brain Res. 62: 541-548.

de Mey, J., F. Aerts, M. De Raeymaeker, G. Daneels, M. Moeremans, B. De Wever, D. D. Vandre, R. B. Vallee, G. G. Borisy, and M. de Brabander (1987) Microtubule associated protein (MAP) 1A: A phosphoprotein associated with spindle fibers and microtubule organizing centers. Prog. Zool. 34: 187-206.

Donatelle, J. M. (1977) Growth of the corticospinal tract and the development of placing reactions in the postnatal rat. J. Comp. Neurol. 175: 207-232.

Farbman, A. I., and L. M. Squinto (1985) Early development of olfactory receptor axons. Dev. Brain Res. 19: 205-213.

Gaarskjaer, F. B. (1985) The development of the dentate area and the hippocampal mossy fiber projection of the rat. J. Comp. Neurol. 241 $154-170$.

Graziadei, P. P. C., and G. A. Monti-Graziadei (1978) Continuous nerve cell renewal in the olfactory system. In Handbook of Sensory Physiology, Development of Sensory Systems, Vol. 9, M. Jacobson, ed., pp. 55-83, Springer-Verlag, Berlin.

Greene, L. A., R. K. H. Liem, and M. L. Shelanski (1983) Regulation of a high molecular weight microtubule-associated protein in $\mathrm{PC} 12$ cells by nerve growth factor. J. Cell Biol. 96: 76-83.

Hammarback, J. A., R. A. Obar, and R. B. Vallee (1989) Molecular cloning of microtubule associated protein 1B. J. Cell Biol. 107: 460a.

Herrmann, H., J. M. Dalton, and G. Wiche (1985) Microheterogeneity of microtubule-associated proteins, MAP-1 and MAP-2, and differential phosphorylation of individual subcomponents. J. Biol. Chem. 260: 5797-5803.

Hinds, J. W., and T. L. Ruffett (1973) Mitral cell development in the mouse olfactory bulb: Reorientation of the perikaryon and maturation of the axon initial segment. J. Comp. Neurol. 151: 281-306.

Hirokawa, N., G. S. Bloom, and R. B. Vallee (1985) Cyloskeletal architecture and immunocytochemical localization of microtubuleassociated proteins in regions of axons associated with rapid axonal transport: The $\beta, \beta^{\prime}$-iminodipropionitrile-intoxicated axon as a model system. J. Cell Biol. 101: 227-239.

Huber, G., and A. Matus (1984) Immunohistochemical localization of microtubule-associated protein 1 in rat cerebellum using monoclonal antibodies. J. Cell Biol. 98: 777-781.

Kumagai, H., M. Imazawa, and K. Miyamoto (1985) Developmental changes in components of chick brain microtubule-associated protein-1 (MAP-1) and tau proteins. J. Biochem. (Tokyo) 97: 529532.

Kuznetsov, S. A., and V. I. Gelfand (1987) $18 \mathrm{kDa}$ microtubule-associated protein: Identification as a new light chain (LC-3) of microtubule-associated protein 1 (MAP-1). FEBS Lett. 212: 145-148.

Kuznetsov, S. A., V. I. Rodionov, E. S. Nadezhdina, D. B. Murphy, 
and V. I. Gelfand (1986) Identification of a $34 \mathrm{kD}$ polypcptide as a light chain of microtubule-associated protein-1 (MAP-1) and its association with a MAP-1 peptide that binds to microtubules. J. Cell Biol. 102: 1060-1066.

Laemmli, U. K. (1970) Cleavage of structural proteins during assembly of the head of bacteriophage T4. Nature 227: 680-685.

Lewis, S. A., P. Sherline, and N. J. Cowan (1986) A cloned cDNA encoding MAP 1 detects a single copy gene in mouse and a brainabundant RNA whose level decreases during development. J. Cell Biol. 102: 2106-2114.

Lewis, S. A., D. Wang, and N. J. Cowan (1988) Microtubule-associated protein MAP 2 shares a microtubule binding motif with tau protein. Science 242: 936-939.

Luca, F. C., G. S. Bloom, and R. B. Vallee (1986) A monoclonal antibody that cross-reacts with phosphorylated cpitopes on two microtubule-associated proteins and two neurofilament polypeptides. Proc. Natl. Acad. Sci. USA 83: 1006-1010.

Matus, A. (1988) Microtubule-associated proteins: Their potential role in determining neuronal morphology. Annu. Rev. Neurosci. 11: 2944.

Matus, A., and B. Riederer (1986) Microtubule-associated proteins in the developing brain. Ann. NY Acad. Sci. 466: 167-179.

McLean, I. W., and P. K. Nakane (1974) Periodate-lysine-paraformaldehyde fixative. A new fixative for immunoelectron microscopy. J. Histochem. Cytochem. 22: 1077-1083.

Papasozomenos, S. C., and L. I. Binder (1987) Phosphorylation determines two distinct species of tau in the central nervous system. Cell Motil. Cytoskel. 8: 210-226.

Paschal, B. M., and R. B. Vallee (1987) Retrograde transport by the microtubule associated protein MAP 1C. Nature 330: 181-183.

Paschal, B. M., H. S. Shpetner, and R. B. Vallee (1987) MAP 1C is a microtubule-activated ATPase that translocates microtubules in vitro and has dynein-like properties. J. Cell Biol. 105: 1273-1282.

Riederer, B., and A. Matus (1985) Differential expression of distinct microtubule associated proteins during brain development. Proc. Natl. Acad. Sci. USA 82: 6006-6009.

Riederer, B., R. Cohen, and A. Matus (1986) MAP5: A novel brain microtubule-associated protein under strong developmental regulation. J. Neurocytol. 15: 763-775.

Sato, C., K. Nishizawa, T. Nakayama, and T. Kobayashi (1984) Fffect upon mitogenic stimulation of calcium-dependent phosphorylation of cytoskeleton-associated 350,000 and $80,000-$ mol-wt polypeptides in quiescent $3 \mathrm{Y} 1$ cells. J. Cell Biol. 100: 748-753.

Schreyer, D. J., and E. G. Jones (1982) Growth and target finding by axons of the corticospinal tract in prenatal and postnatal rats. Neuroscience 7: 1837-1853.

Shaw, G., and K. Weber (1982) Differential expression of neurofilament triplet proteins in brain development. Nature 298: 277-279.

Shaw, G., M. Osborn, and K. Weber (1986) Reactivity of a panel of neurofilament antibodies on phosphorylated and dephosphorylated neurofilaments. Eur. J. Cell Biol. 42: 1-9.
Shiomura, Y., and N. Hirokawa (1987) The molccular structure of microtubule-associated protein $1 \mathrm{~A}$ (MAP 1A) in vivo and in vitro. An immunoelectron microscopy and quick-freeze, deep-etch study. J. Neurosci. $7:$ 1461-1469.

Stefanini, M., C. de Martino, and L. Zamboni (1967) Fixation of ejaculated spermatozoa for electron microscopy. Nature 216: 173174.

Sternberger, L. A., and N. H. Sternberger (1983) Monoclonal antibodies distinguish phosphorylated and nonphosphorylated forms of neurofilaments in situ. Proc. Natl. Acad. Sci. USA 80: 6126-6130.

Theurkauf, W. E., and R. B. Vallee (1982) Molecular characterization of the cAMP-dependent protein kinase bound to microtubule-associated protein 2. J. Biol, Chem. 257: 3284-3290.

Vallee, R. B. (1980) Structure and phosphorylation of microtubuleassociated protcin 2 (MAP 2). Proc. Natl. Acad. Sci. USA 77: 32063210 .

Vallee, R. B. (1982) A taxol-dependent procedure for the isolation of microtubules and microtubule-associated proteins (MAPS). J. Cell Biol. 92: 435-442.

Vallee, R. B. (1986a) Reversible assembly purification of microtubules without assembly-promoting agents and further purification of tubulin, microtubule-associated proteins, and MAP fragments. Methods Enzymol. 134: 89-104.

Vallee, R. B. (1986b) Purification of brain microtubules and microtubule-associated proteins 1 using taxol. Methods Enzymol. 134: 104116

Vallee, R. B., and S. E. Davis (1983) Low molecular weight microtubule associated proteins are light chains of microtubule-associated protein 1 (MAP 1). Proc. Natl. Acad. Sci. USA 80:1342-1346.

Vallee, R. B., and F. C. Luca (1985) Light chain content and other criteria for the identification of microtubule-associated protein $1 \mathrm{~A}$ and microtubule-associated protein 1B. In Microtubules and Microtubule Inhibitors, M. de Brabander and J. de Mey, eds., pp. 129-144, Elsevier North-Holland, Amsterdam.

Vallee R. B., M. DiBartolomeis, and W. E. Theurkauf (1981) A protein kinase bound to the projection portion of MAP 2 (microtubule associated protein 2). J. Cell Biol. 90: 568-572.

Vallee, R. B., G. S. Bloom, and F. C. Luca (1986) Differential structure and distribution of the high molecular weight brain microtubule associated proteins, MAP 1 and MAP 2. Ann. NY Acar. Sci. 466: 134144.

Vallee, R. B., B. M. Paschal, H. S. Shpetner, and J. S. Wall (1988) Microtubule associated protein MAP 1C from brain is a two-headed cytosolic dynein. Nature 332: 561-563.

Voter, W. A., and H. P. Erickson (1982) Electron microscopy of MAP 2 (microtubule associated protein 2). J. Ultrastruct. Res. 80:374382.

Wood, J. N., and B. H. Anderton (1981) Monoclonal antibodies to mammalian neurofilaments. Biosci. Kep. 1: 263-268. 